\title{
Rapid adaptation of signaling networks in the fungal pathogen Magnaporthe oryzae
}

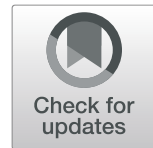

Stefan Bohnert ${ }^{1}$, Luis Antelo ${ }^{1}$, Christiane Grünewald ${ }^{2}$, Alexander Yemelin ${ }^{1}$, Karsten Andresen ${ }^{2}$ and Stefan Jacob ${ }^{1,2^{*}}$ (D)

\begin{abstract}
Background: One fundamental question in biology is how the evolution of eukaryotic signaling networks has taken place. "Loss of function" (lof) mutants from components of the high osmolarity glycerol (HOG) signaling pathway in the filamentous fungus Magnaporthe oryzae are viable, but impaired in osmoregulation.

Results: After long-term cultivation upon high osmolarity, stable individuals with reestablished osmoregulation capacity arise independently from each of the mutants with inactivated HOG pathway. This phenomenon is extremely reproducible and occurs only in osmosensitive mutants related to the HOG pathway - not in other osmosensitive Magnaporthe mutants. The major compatible solute produced by these adapted strains to cope with high osmolarity is glycerol, whereas it is arabitol in the wildtype strain. Genome and transcriptome analysis resulted in candidate genes related to glycerol metabolism, perhaps responsible for an epigenetic induced reestablishment of osmoregulation, since these genes do not show structural variations within the coding or promotor sequences.

Conclusion: This is the first report of a stable adaptation in eukaryotes by producing different metabolites and opens a door for the scientific community since the HOG pathway is worked on intensively in many eukaryotic model organisms.
\end{abstract}

Keywords: Rapid adaptation, HOG pathway, Magnaporthe oryzae, Rewiring, Reestablishment of osmoregulation, Epigenetics, Evolution of signaling networks, Suppressor

\section{Background}

Adaptation is a central biological process that underlies diverse phenomena from the acquisition of antibiotic resistance by microbes to the evolution of niche specialization [1]. Most of these experimental analyses focused on bacterial systems studying the evolution of populations and genetic structures, the adaptive profit of new functions and the consequences of competition dynamics in large populations. The most prominent example to address molecular mechanisms of evolution is the Escherichia coli long-term evolution experiment [2]. It reveals complex dynamics, characterized by rapid adaptation, competition between beneficial mutations and extensive genetic parallelism in bacterial populations. However, until now, relatively little has been discovered about the mechanisms of molecular

\footnotetext{
* Correspondence: jacob@ibwf.de

'Institut für Biotechnologie und Wirkstoff-Forschung gGmbH (IBWF),

Erwin-Schrödinger-Str. 56, D-67663 Kaiserslautern, Germany

${ }^{2} J o h a n n e s$ Gutenberg-University Mainz, Mikrobiologie und Weinforschung

am Institut für Molekulare Physiologie, Johann-Joachim-Becherweg 15, D-55128 Mainz, Germany
}

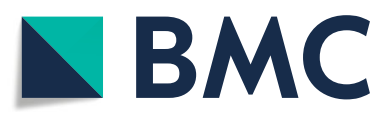

(c) The Author(s). 2019 Open Access This article is distributed under the terms of the Creative Commons Attribution 4.0 International License (http://creativecommons.org/licenses/by/4.0/), which permits unrestricted use, distribution, and

reproduction in any medium, provided you give appropriate credit to the original author(s) and the source, provide a link to the Creative Commons license, and indicate if changes were made. The Creative Commons Public Domain Dedication waiver (http://creativecommons.org/publicdomain/zero/1.0/) applies to the data made available in this article, unless otherwise stated.

evolutionary adaptation in eukaryotes. One fundamental question in biology is how eukaryotic signaling pathways evolve to adapt towards changing environmental situations. The adaptation of molecular mechanisms from signaling networks and the question why the networks show a high level of complexity are of particular interest [3]. Over the last few years, the understanding of the molecular and biochemical principles of evolution have increased dramatically $[4,5]$. Epigenetic modulation, such as DNA methylation, chromatin modification and noncoding RNAs, are found to be involved in the multigenerational transmission of phenotypes and transgenerational inheritance [6]. Nevertheless, there has been little detailed information about how phenotypic changes rest on the rate and the nature of the underlying genotypic or epigenetic changes [7]. Regulatory signaling networks represent the causality of developmental processes. The big challenges regarding regulatory networks generally remain in understanding how genetic variants generate phenotypes [8]. Genomic sequence variants influence the regulation of the expression of genes that encode proteins generating signaling patterns and execute 
differentiation or even adaptation to changing environments [9]. Microbial signal transduction pathways apply far more modular mechanisms to define their input-output interactions than classical metabolic pathways [10]. Thus, in addition to their core catalytic function, the proteins often contain multiple independently folding domains or motifs that mediate connectivity by interacting with other signaling elements [11]. These elements are found in different combinations with different signaling functions, suggesting insertion and recombination of modules may be a common mechanism of the evolution of new signaling networks [12]. Furthermore, protein domains are extensively recombined in order to facilitate functional innovations $[5,13]$. Prominent examples of pathways with a modular architecture mediated by scaffold proteins are signaling pathways in yeast, including several mitogen-activated protein kinase (MAPK) cascades [12, 14]. Attachment of different scaffolds could, in principle, be sufficient to generate new signaling pathways from combinations of preexisting kinases [15]. Canonical MAPK cascades in fungi were reputed to be responsible for a large part of signal transduction. These MAPK pathways contain signal modules in which an activated MAPK kinase kinase (MAPKKK) activates a MAPK kinase (MAPKK), which then activates a MAPK (extracellular signal-regulated kinase: ERK). The MAPK targets comprise transcription factors, phosphatases, protein kinases and other classes of proteins. They regulate physiological processes, cellular morphology, cell cycle progression, metabolism and gene expression in response to various extracellular signals or environmental stresses [16]. Such MAPK pathways appear ideal for exploring the fundamental mechanisms of evolutionary adaptation. Three distinct MAPK genes - MoKSS1 (formerly MoPMK1), MoSLT2 (formerly MoMPS1), and MoHOG1 (formerly MoOSM1) [17] - have been identified in the genome of the filamentous rice blast fungus Magnaporthe oryzae (Pyricularia oryzae) and possess diverse roles in cellular signaling and pathogenesisrelated development [18-20]. The high osmolarity glycerol (HOG) pathway is responsible for osmoregulation in fungi and seems to operate independently of the MoKSS1 and MoSLT2 pathways in M. oryzae by regulating the biosynthesis of arabitol and glycerol [20]. Upon high external osmolarity, cells have to quickly recover volume by water influx due to the accumulation of compatible solutes, i.e. mainly arabitol in the rice blast fungus. The HOG pathway in M. oryzae comprises the MoSln1p/MoHik1p-MoYpd1pMoSsk1p phosphorelay system and the MAPK cascade MoSsk2p-MoPbs2p-MoHog1 (Fig. 1).

The HOG pathway in M. oryzae was previously found to be an attractive system to study the basics of physiological functions of signaling proteins and the mode of action of agricultural fungicides, such as fludioxonil [21-23]. M. oryzae-mutants lacking components of the HOG pathway are osmosensitive, since they showed a dramatically

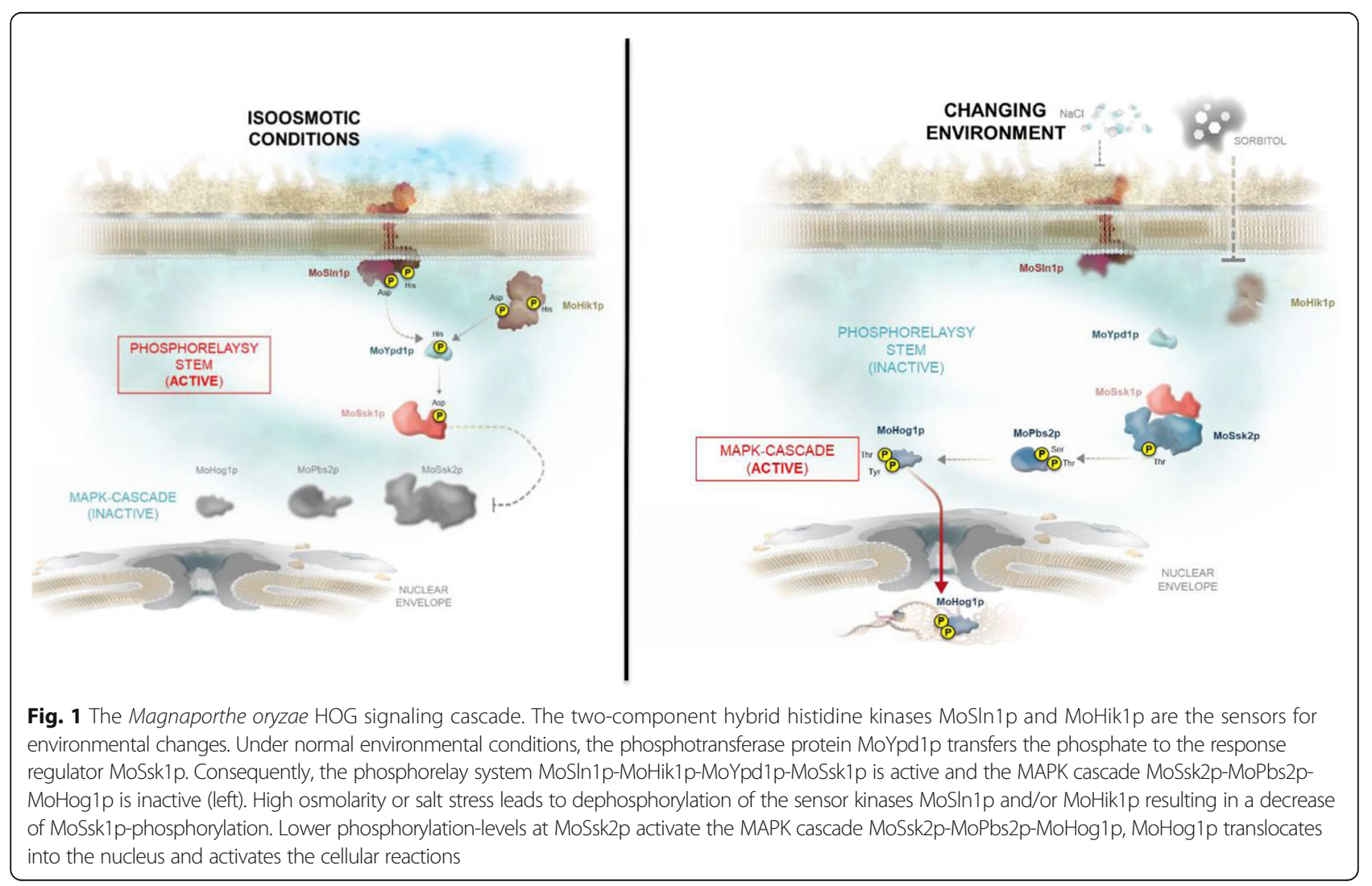


reduced ability to accumulate arabitol in the mycelium [20]. In the study presented, osmosensitive "loss of function" (lof) mutants $\Delta$ Mohog1, $\Delta$ Mopbs2, $\Delta$ Mossk2, $\Delta M o s s k 1$ and $\Delta$ Moypd1 were cultivated upon osmotic stress, resulting in stable individuals outgrowing from the mycelium of each lof mutant after four weeks of stress. These adapted individuals show a reestablished osmoregulation and produce glycerol and not arabitol as the major compatible solute upon osmotic shock. To the best of our knowledge, we present such an independent and stable adaptation of individuals outgrowing from lof mutants for the first time. Furthermore, we believe that this study will open the door for many research groups, since this rapid adaptation phenomenon will be easily addressable in a broad spectrum of eukaryotic model organisms.

\section{Results}

\section{"Adapted" mutants arise out of independent "loss of} function" strains upon long-term cultivation on stress Apart from molecular biology techniques and nextgeneration sequencing approaches, classical vegetative growth assays were used to characterize potential functions of genes associated with osmoregulation to study the HOG pathway in $M$. oryzae. Therefore, we cultivated the previously generated lof mutants $\Delta$ Mohog1, $\Delta$ Mopbs2, $\Delta$ Mossk2, $\Delta$ Mossk1, $\Delta$ Moypd1, $\Delta$ Mohik1 and $\Delta M o s \ln 1$ [21] on different stress-inducing media to compare them with the wildtype strain. Mutants with an inactivated HOG pathway are sensitive to osmotic stress and resistant to the fungicide fludioxonil [21]. We noticed in the course of these assays that individual mycelium parts grew out of the sensitive lof mutants $\Delta$ Mohog1, $\Delta$ Mopbs2, $\Delta$ Mossk2, $\Delta$ Mossk1 and $\Delta$ Moypd1 after cultivation for at least four to six weeks under continuous salt stress (Fig. 2).

We isolated these individual mycelium parts in order to separate them as pure cultures ready for further investigations and named them $\Delta M o h o g 1$ (adapted), $\Delta M o p b s 2$ (adapted), $\Delta M o s s k 2$ (adapted), $\Delta M o s s k 1$ (adapted) and $\Delta$ Moypd1(adapted). We have not been able to get adapted strains from the mutants $\Delta M o s \ln 1$ and $\Delta M o h i k 1$ in the conditions tested so far. That underpins the hypothesis from our previous studies that the twocomponent hybrid histidine kinase (HK) MoHik1p and the HK MoSln1p can partially take over the function from each other [24] and, thus, the selection pressure maybe not sufficient for an adaptation event in $\Delta M o s \ln 1$ and $\Delta$ Mohik1. Furthermore, it was not possible for us to isolate adapted strains from HOG pathway-independent osmosensitive Magnaporthe-mutant strains, i.e. $\Delta$ Mostu1 (transcription factor in cAMP/PKA signaling pathway, $\Delta$ Mogpd1 (glycerol-3-phosphate dehydrogenase) or $\Delta M o s k n 7$ (response regulator protein). Of course, we checked in the adapted strains whether the genes originally inactivated in the "parent" lof mutants were still inactivated in order to avoid any possibility of contaminations or confusions about mixed cultures. We did this for all adapted strains using ITS-sequencing and southern blot analyses (Additional file 2: Figure S1).

In empirical investigations, a combination of different vegetative growth assays was used to characterize the "rapid adaptation frequency" in the different lof mutants. Twenty mutant strains of each of $\Delta$ Mohog1, $\Delta M o p b s 2$, $\Delta$ Mossk2, $\Delta$ Mossk1, and $\Delta$ Moypd 1 were grown continuously on solid complete medium (CM) including $1 \mathrm{M}$ $\mathrm{KCl}$ or $1.5 \mathrm{M}$ sorbitol as stress-inducing agents. Several adapted strains arose out of the lof mutants in each plate, being able to grow much faster under the stress condition. The adapted strains were then transferred onto $\mathrm{CM}$ without stressors for the following two weeks. Subsequently, we transferred the colonies onto repeated stress medium to investigate in which strains the "adaptation" is stable and identified the stably adapted strains (Additional file 3: Figure S2). Notably, we were able to identify more adapted strains from $\triangle M o p b s 2$ and $\triangle M o y p d 1$ under salt stress than under sorbitol stress. By contrast, we obtained more adapted strains under sorbitol stress than under salt stress from $\Delta$ Mossk 2 and $\Delta$ Mossk1 (Additional file 3: Figure S2).

\section{Osmoregulation is permanently restored in the adapted mutants}

The strains $\Delta M o h o g 1$ (adapted), $\Delta M o p b s$ (adapted), $\Delta M o s s-$ k2(adapted), $\Delta$ Mossk1(adapted) and $\Delta M o y p d 1$ (adapted)
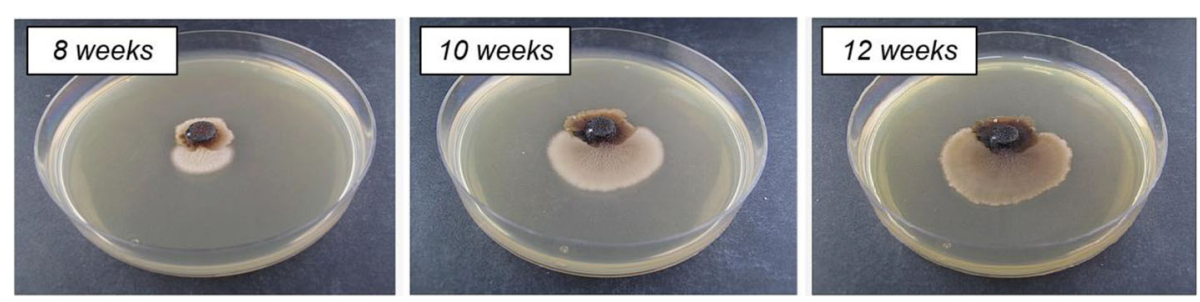

Fig. 2 Example of Magnaporthe oryzae "loss of function" (lof) strains $\Delta$ Mohog1 and $\Delta$ Mohog 1(adapted) after long-term cultivation upon salt stress. The lof strain $\Delta$ Mohog 1 was grown on complete medium (CM) inclusive $1 \mathrm{M} \mathrm{KCl}$ at $26^{\circ} \mathrm{C}$. The $\Delta$ Mohog 1 mutant (dark brownish colony) was found to be highly sensitive towards $1 \mathrm{M} \mathrm{KCl}$, whereas the outgrowing $\Delta$ Mohog 1 (adapted) strain (bright colony) was able to grow much faster 
displayed significant differences in growth speed on salt stress compared to their "parent-strains," the lof mutants $\Delta$ Mohog1, $\Delta$ Mopbs2, $\Delta$ Mossk2, $\Delta$ Mossk1 and $\Delta$ Moypd1 (Fig. 3 [1]). All lof mutants were strongly sensitive towards $1 \mathrm{M} \mathrm{KCl}$ stress, whereas all the adapted strains were less sensitive, similar to the wildtype strain (Fig. 3 [1], lower row, colonies [A]). Particular attention has to be paid to the finding that adapted strains, which were pre-cultivated on normal CM (unstressed conditions) and then transferred back to the repeated salt stress, were found to grow as fast as those taken directly from stress conditions and, thus, being able to adapt to $\mathrm{KCl}$ stress immediately (Fig. 3 [1], colonies [C]). In conclusion, the mutations/alterations within $\Delta M o h o g 1$ (adapted), $\Delta M o p b s 2$ (adapted), $\Delta$ Mossk2(adapted), $\Delta M o s s k 1$ (adapted) and $\Delta M o y p-$ $d 1$ (adapted) appear to be stable. Similar results to the growth assays on solid media could be observed in liquid cultures upon $\mathrm{KCl}$ stress (Fig. 3 [2]) and sorbitol stress (Additional file 4: Figure S3).
Glycerol is the major compatible solute produced by the adapted strains after salt shock

Intracellular production of compatible solutes was determined by high-performance anion-exchange chromatography with pulsed amperometric detection (HPAEC-PAD) and compared to compatible solute production of the lof mutants and the wildtype strain to further investigate the phenomenon of restored osmoregulation in $\Delta M o h o g 1$ (adapted), $\Delta M o p b$ s2(adapted), $\Delta$ Mossk2(adapted), $\Delta$ Mossk1(adapted) and $\Delta$ Moypd1(adapted). Hyperosmotic shock was imposed by $0.5 \mathrm{M} \mathrm{KCl}$ stress towards the fungal strains, and the intracellular levels of the major osmolytes mannitol, trehalose, arabitol and glycerol were determined. No increases in the mannitol and trehalose levels were detected in the lof mutants and the adapted strains after osmotic shock (data not shown). A slight increase in the mannitol level was detected and no significant change for the trehalose level of the wildtype strain (data not shown). Similar to data from [20], arabitol was

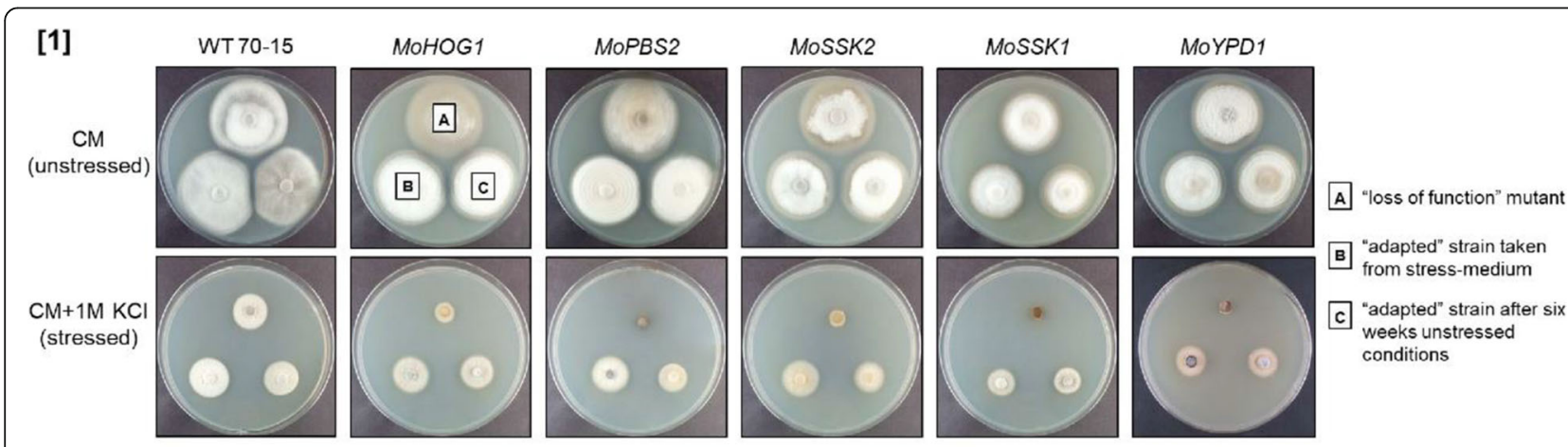

[2]

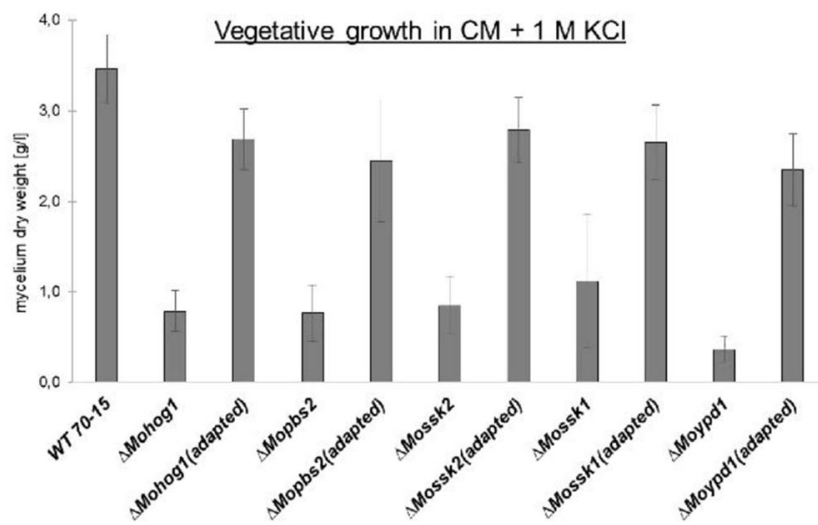

Fig. 3 [1] Stable reestablishment of osmoregulation in adapted strains. Vegetative growth of the Magnaporthe oryzae wildtype strain, mutants with inactivated components of the HOG signaling cascade and the "adapted" strains upon salt stress. The fungal colonies were grown on CM (upper row) and $\mathrm{CM}$ including $1 \mathrm{M} \mathrm{KCl}$ (lower row) for $7 \mathrm{~d}$ at $26^{\circ} \mathrm{C}$. $\mathrm{A}, \mathrm{B}$ and $\mathrm{C}$ are representative for each plate. $\mathrm{A}=$ lof mutant, $\mathrm{B}=$ "adapted" strain taken directly from CM inclusive $1 \mathrm{M} \mathrm{KCl}$ ("adaptation" conditions), and C = "adapted" strain after six weeks of preincubation on CM (to have long-term unstressed conditions before this assay). In the case of the wildtype strain (left), the three cultures on each test plate used in the assays were from the M. oryzae wildtype strain 70-15 cultivated in an equal manner. [2] Mycelium dry weight of the Magnaporthe oryzae wildtype strain, mutants with inactivated components of the HOG signaling cascade and the "adapted" strains after growth in liquid culture upon $\mathrm{KCl}$ stress. The fungal colonies were grown in $250 \mathrm{ml} \mathrm{CM}$ including $1 \mathrm{M} \mathrm{KCl}$ for $6 \mathrm{~d}$ at $26^{\circ} \mathrm{C}$ and $120 \mathrm{rpm}$. Error bars represent the standard deviation of three biological replicates of each strain 
found to be the major intracellular compatible solute produced by the wildtype strain after osmotic shock (Fig. 4).

By contrast, the lof mutants $\Delta$ Mohog1, $\Delta$ Mopbs2, $\Delta$ Mossk2, $\Delta$ Mossk1 and $\Delta$ Moypd1 were not able to produce either arabitol or glycerol in significant amounts. Interestingly, it was found that all the adapted strains $\Delta$ Mohog1(adapted), $\Delta M o p b s 2$ (adapted), $\Delta$ Mossk2(adapted), $\Delta M o s s k 1$ (adapted) and $\Delta$ Moypd1(adapted) responded to hyperosmotic stress by accumulating high amounts of glycerol rather than arabitol (Fig. 4). Based on these observations, we conclude that glycerol may somehow compensate for the lack of arabitol upon salt stress in the adapted strains.

\section{Fludioxonil susceptibility is restored in the adapted mutants}

Vegetative growth assays were conducted using minimal medium (MM) and $\mathrm{MM}$ including $10 \mu \mathrm{g} / \mathrm{ml}$ fludioxonil to further investigate whether fludioxonilsusceptibility and not only osmoregulation is restored in $\Delta M o h o g 1$ (adapted), $\Delta M o p b s 2$ (adapted), $\Delta M o s s k 2$ (adapted), $\Delta$ Mossk1(adapted) and $\Delta$ Moypd1(adapted) (Fig. 5).

Apart from the osmoregulation capacity, fludioxonil sensitivity was reconstituted in the adapted strains. The HOG pathway lof mutants were resistant towards the fungicide (Fig. 5, colonies [A], lower row), whereas all adapted strains were susceptible, but not quite as strongly as the wildtype strain (Fig. 5 , colonies [B], lower row). Similar to the findings concerning salt stress presented previously in Fig. 3, the adapted strains, which were pre-cultivated in unstressed conditions for a long time, showed the same phenotype as the adapted strains taken directly from stress medium (Fig. 5, colonies [C], lower row).

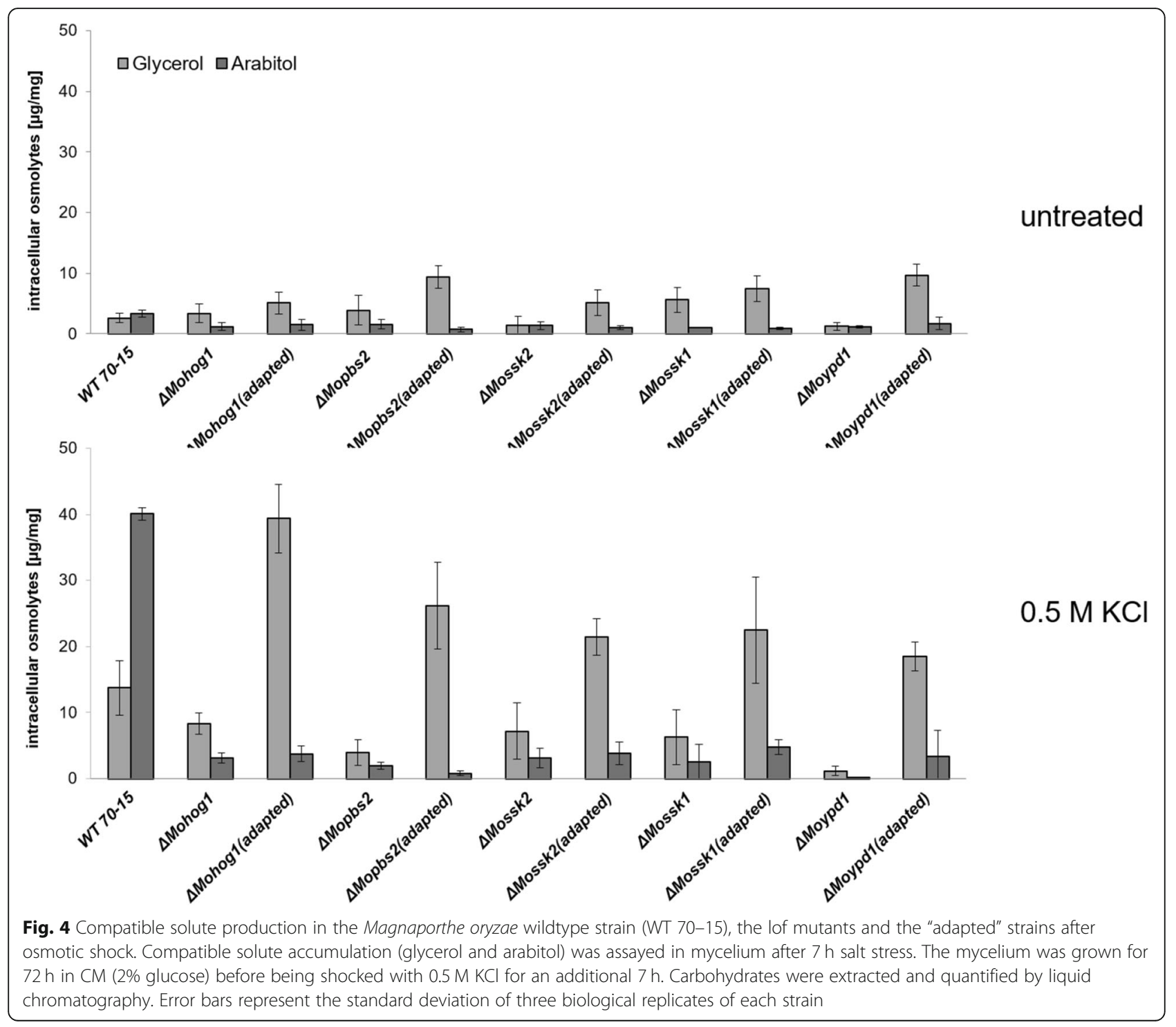




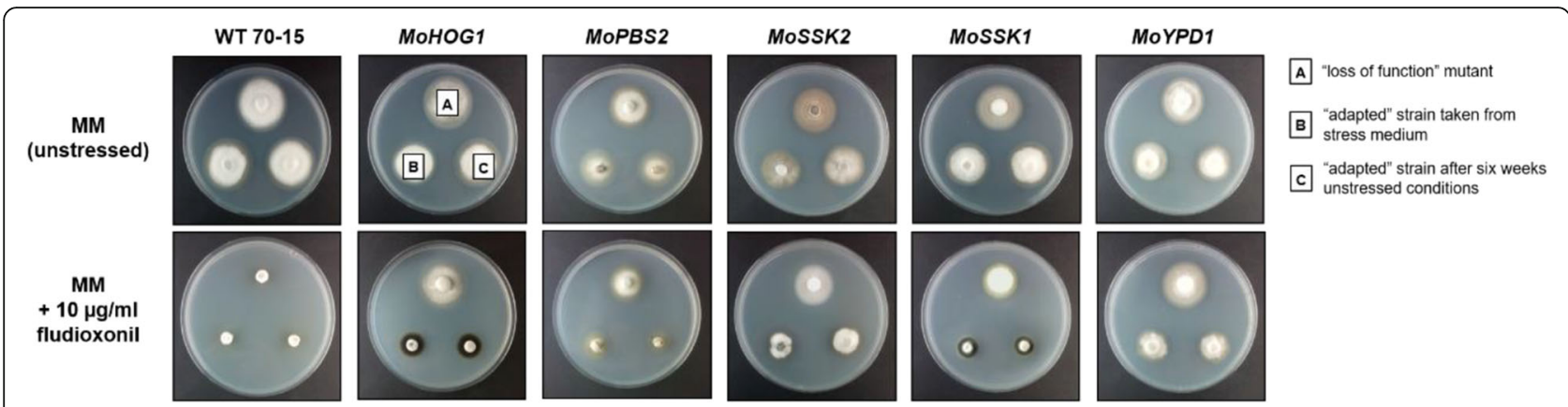

Fig. 5 Stable vegetative growth of the Magnaporthe oryzae wildtype strain (WT 70-15), mutants with inactivated components of the HOG signaling cascade and the "adapted" strains upon fludioxonil treatment. The fungal colonies were grown on minimal medium (MM, upper row) and on MM including $10 \mu \mathrm{g} / \mathrm{ml}$ fludioxonil (lower row) for $7 \mathrm{~d}$ at $26^{\circ} \mathrm{C}$. A, B and C are representative for each plate. $\mathrm{A}=$ lof mutant, $\mathrm{B}=$ "adapted" strain taken directly from CM including $1 \mathrm{M} \mathrm{KCl}$ ("adaptation" conditions) and $\mathrm{C}=$ "adapted" strain after six weeks of preincubation on CM (to have long-term unstressed conditions before this assay to show the memory effect). In the case of the wildtype strain (left), the three cultures on each test plate used in the assays were from the M. oryzae wildtype strain 70-15 cultivated in an equal manner

Fludioxonil sensitivity in the adapted strains is not dependent on the production of arabitol or glycerol Fludioxonil induces a hyperactivation of the HOG pathway and, thus, a continuous stress response towards high osmolarity. We found, by using HPAEC-PAD analytics, that fludioxonil treatment resulted in the production of arabitol and glycerol in the wildtype strain (Fig. 6). We conducted the experiments with the lof mutants and the adapted strains $\Delta M o h o g 1$ (adapted), $\Delta M o p b s 2$ (adapted), $\Delta$ Mossk2(adapted), $\Delta$ Mossk1(adapted) and $\Delta M o y p d 1$ (adapted) to check whether fludioxonil-dependent production of the compatible solutes was altered in the adapted strain. The fungal cultures were grown in liquid CM ( $2 \%$ glucose) and stressed with $10 \mu \mathrm{g} / \mathrm{ml}$ fludioxonil. As

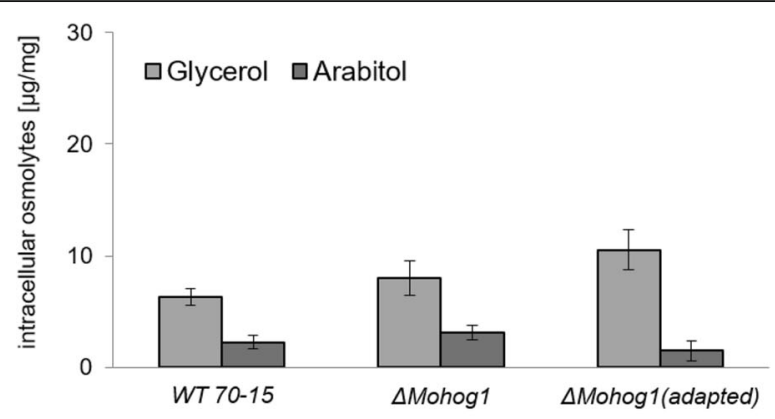

untreated

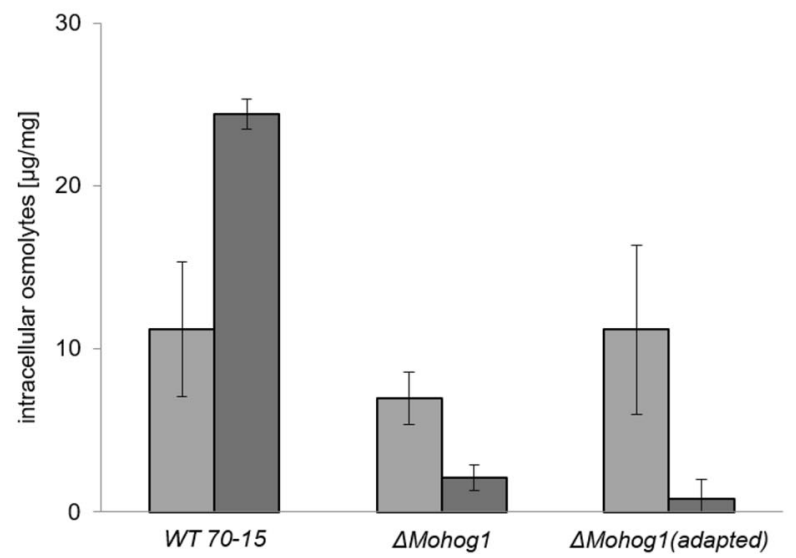

$10 \mu \mathrm{g} / \mathrm{ml}$ Fludioxonil

Fig. 6 Compatible solute production in the wildtype strain, $\Delta$ Mohog1 and $\Delta$ Mohog 1(adapted) upon fludioxonil treatment. Compatible solute accumulation (glycerol and arabitol) was assayed in the mycelium of the wildtype strain, $\Delta$ Mohog 1 and $\Delta$ Mohog 1 (adapted) after $7 \mathrm{~h}$ treatment with $10 \mu \mathrm{g} / \mathrm{ml}$ fludioxonil. The mycelium was grown for $72 \mathrm{~h}$ in CM (2\% glucose) before being shocked with $10 \mu \mathrm{g} / \mathrm{ml}$ fludioxonil for an additional $7 \mathrm{~h}$. Carbohydrates were extracted and quantified by liquid chromatography. Error bars represent the standard deviation of three biological replicates of each strain 
expected, we did not find increased compatible solute production upon fludioxonil-treatment in the lof mutants. Exemplarily, we present the data for $\Delta$ Mohog1 (Fig. 6).

Interestingly, no increase of arabitol or glycerol production was detectable in the fludioxonil-susceptible adapted strains in the presence of the fungicide (Fig. 6). It has to be pointed out that the metabolic response of the adapted strains after fludioxonil treatment is different compared to the compatible solute production we observed upon $\mathrm{KCl}$ treatment (Fig. 4). All the adapted strains $\Delta M o h o g 1$ (adapted), $\Delta M o p b s 2$ (adapted), $\Delta M o s s-$ k2(adapted), $\Delta$ Mossk1(adapted) and $\Delta$ Moypd1(adapted) responded to salt stress by accumulating high amounts of glycerol, whereas this is not the case under fludioxonil stress. In conclusion, fludioxonil sensitivity in the adapted strains does not appear to be dependent on compatible solute production.

\section{Reestablished osmoregulation does not complement reduced virulence of the lof mutants}

The lof mutants of the HOG pathway in M. oryzae were found to be reduced in virulence towards rice plants compared to the wildtype strain. Interestingly, $\Delta M o h o-$ g1(adapted), $\Delta$ Mopbs2(adapted), $\Delta M o s s k 2$ (adapted) and $\Delta$ Mossk1(adapted) were not found to be as virulent as the wildtype strain, and rather less virulent than the lof mutants (Additional file 5: Figure S4). We were not able to conduct the pathogenicity assays regarding $\Delta$ Moypd1(adapted), since the mutant failed to produce conidia exactly like $\Delta$ Moypd 1 [21].

\section{There are no relevant structural variations on DNA-level} in the genomes of adapted strains

We had a deeper look at the genomes of $\Delta M o h o g 1$ compared to $\Delta M o h o g 1$ (adapted) in order to find out the cause of that rapid adaptation in the adapted strains. We also added data from the genome sequencing of $\Delta M o p b s 2$ ( $a$ dapted) to strengthen the analysis and narrow down the outcome of putative candidate genes showing structural variations in the adapted strains. Single nucleotide variations (SNVs) and short indels were detected for $\Delta M o h o g 1(a-$ dapted), $\Delta M o p b s 2$ (adapted) and $\Delta M o h o g 1$ in comparison with the reference sequence of the wildtype strain. The resulting variants were further annotated based on their chromosomal location and biological effects, such as synonymous/non-synonymous single-nucleotide polymorphisms (SNPs), upstream/downstream, untranslated regions (UTRs) and intergenic regions (Additional file 1: SVs summary). The ratio of transition and transversion was also calculated for single nucleotide variation. Over $80 \%$ of all SNPs detected were found to be located outside exons and a significant enrichment in regions adjacent to exons and UTRs was detected. Furthermore, in silico protein modelling suggested that several non-synonymous SNPs are probably direct targets of selection, as they lead to amino acid replacements in functionally important sites of proteins. Hence, the structural variation discovery analysis of smallscale $(<20 \mathrm{bp})$ and large-scale variations ( $>20 \mathrm{bp})$ such as frameshift, stop codon insertion resulted in a list of three genes (five putative gene variants) in the overlap of $\Delta M o h o$ g1(adapted) and $\Delta M o p b s 2$ (adapted), but none of them leads to a protein effect. The variations are only transitions not changing the amino acid composition of the corresponding proteins. Furthermore, we checked the homologous gene loci of the known yeast suppressor mutation genes RSG1 (RHB1) [25], SOO1 [26], SGD1 [27] and PMK1 (KSS1) [28] intensively. Within all these loci, we could not identify structural variations in the genome of the adapted strains $\Delta$ Mohog1 (adapted) and $\Delta M o p b s 2$ (adapted).

Since regulatory gene elements, such as promoters, are of prior interest regarding their direct influence on gene expression alteration, we decided to investigate the presence of genetic structural variations in the putative promoter regions of all annotated genes in the $M$. oryzae genome. The promoter region was defined as the region on the genomic DNA 1500 bp upstream of each annotated gene start codon. We performed a structural variation discovery analysis of small-scale $(<20 \mathrm{bp})$ and large-scale variations $(>20 \mathrm{bp})$ resulting again in no significant variations in the overlap of the promoter regions of $\Delta$ Mohog1(adapted) and $\Delta$ Mopbs2(adapted) (Additional file 6: Figure S5 [A]). We considered here only insertions and deletions as a "polymorphism type" and insertions, truncations and frame-shifts as a "protein effect."

\section{Differential transcriptomic profiles in the adapted strains in response to osmotic stress}

Next-generation sequencing analysis of RNA samples from the wildtype strain, $\Delta$ Mohog1 and $\Delta M o h o g 1$ (adapted) before and after $25 \mathrm{~min}$ salt stress $(0.5 \mathrm{M} \mathrm{KCl})$ should present insights into transcriptional changes which may be responsible for the adaptation phenomenon observed (methods for cultivation before RNA-isolation, see [29]). A principal component analysis was performed to characterize the relationship between the strains analyzed. The processed transcriptome data of $\Delta$ Mohog1 (untreated), $\Delta$ Mohog1 (25 min $0.5 \mathrm{M} \mathrm{KCl}$-stress), $\Delta$ Mohog1(adapted) (untreated) and $\Delta$ Mohog1(adapted) (25 min $0.5 \mathrm{M} \mathrm{KCl-stress)} \mathrm{appears} \mathrm{to}$ form distinct clusters within each sample group of strain samples investigated (Fig. 7a).

Since the principal component analysis revealed distinct differences on transcriptomes of corresponding strains, we decided to follow up by clustering the genes according to their expression followed by construction of a co-expression network. In the clustering analysis, represented by a heat map visualization, the fact that the 


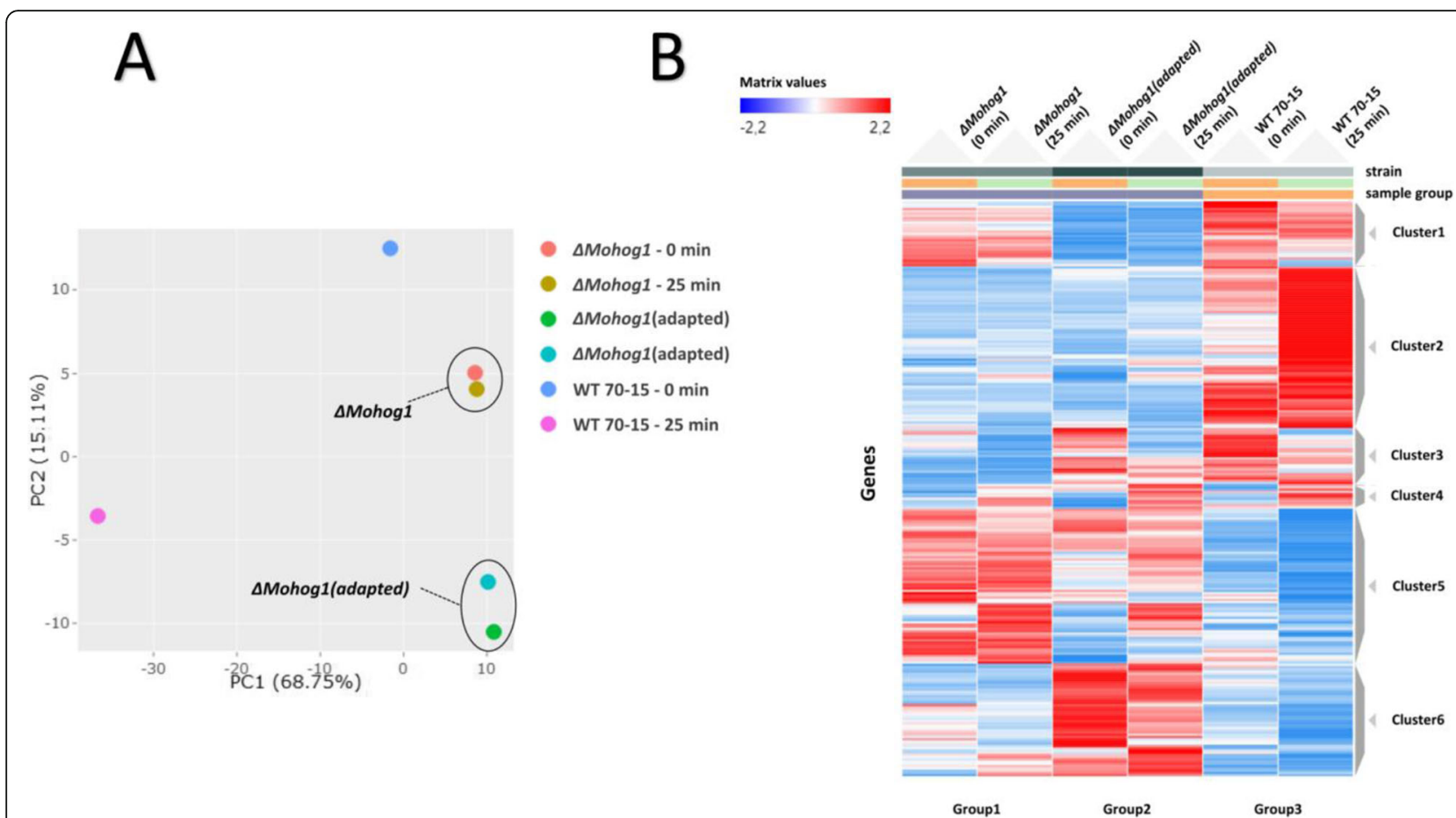

Fig. 7 RNA-sequencing (Seq) data processing. a Principal component analysis results. The figure displays a three-dimensional scatter plot of the first three principal components (PCs) of the data. Each point represents an RNA-Seq sample. Samples with similar gene expression profiles are clustered together. Sample groups are indicated by using different colors as indicated in the legend provided. $\mathbf{b}$ Heat map of transcriptional regulation patterns of the wildtype strain, $\Delta$ Mohog 1 and $\Delta$ Mohog 1(adapted) after 25 min salt stress (Clustergrammer analysis). The figure contains a heat map displaying the expression profile of the top 500 differential expression genes (DEGs) for each sample in the RNA-Seq dataset. The set of mutant strains $\Delta$ Mohog 1 and $\Delta$ Mohogl (adapted) prior and after salt stress was compared to wildtype strain $70-15$ (indicated in the figure as sample group) for perturbation contrast. Each row of the heat map represents a gene, each column represents a sample and each cell displays normalized gene expression values

transcript value is strongly different in $\Delta M \operatorname{Mohog} 1(a$ dapted) compared to the WT 70-15 and $\Delta M o h o g 1$, even in untreated conditions, is clearly visible (Fig. 7b). Cluster 6 is significantly exclusively upregulated and cluster 1 is harboring exclusively down-regulated genes in $\Delta M o$ hog1(adapted), whereas exclusively up-regulated genes in the WT 70-15 could be found in cluster 2 (Fig. 7b).

\section{Glycerol metabolism-associated genes are affected in the adapted strains}

To investigate, whether the groups of differentially expressed genes (DEGs) are functionally related, we performed a gene ontology (GO) enrichment analysis to determine the biological functions associated to them. Generally, this approach helps to highlight groups of genes with coherent biological functions that are presumably acting in coordination in response to salt stress. The clustering analysis was employed over the whole gene co-expression network and in a selected subset or cluster of interest. The result indicated that there were several significantly enriched terms of DEGs, from which the most representative are "lipid biosynthetic process," "glutamine family amino acid metabolic process," "carbohydrate transport," "dephosphorylation" and "carboxylic acid biosynthetic process" (Fig. 8).

This enrichment analysis suggests that the highly connected genes from the largest cluster in the network are involved in the regulation of complementary processes triggered by salt stress.

In order to follow up the results of glycerol-production in the adapted strains, we further investigated most of the genes potentially contributing to the production, metabolism or transport of glycerol. However, we checked these genes presented resulting in a list of homologous genes potentially related to the production, metabolism or transport of glycerol from a database- and literature-based approach (Table 1).

The analysis resulted in a set of candidate genes which were found to be upregulated in both the salt stress samples of the $\Delta$ Mohog1(adapted) and the wildtype strain, whereas these genes were not regulated in the lof mutant $\Delta$ Mohog1 (Table 1, yellow marked). Among these candidates, we identified genes encoding the glycerol $\mathrm{H}^{+}$-symporter MoSlt1p (MGG_09852), one phosphoglycerate mutase (MGG_06642,), one glycerol-3-phosphate dehydrogenase (MGG_00067 


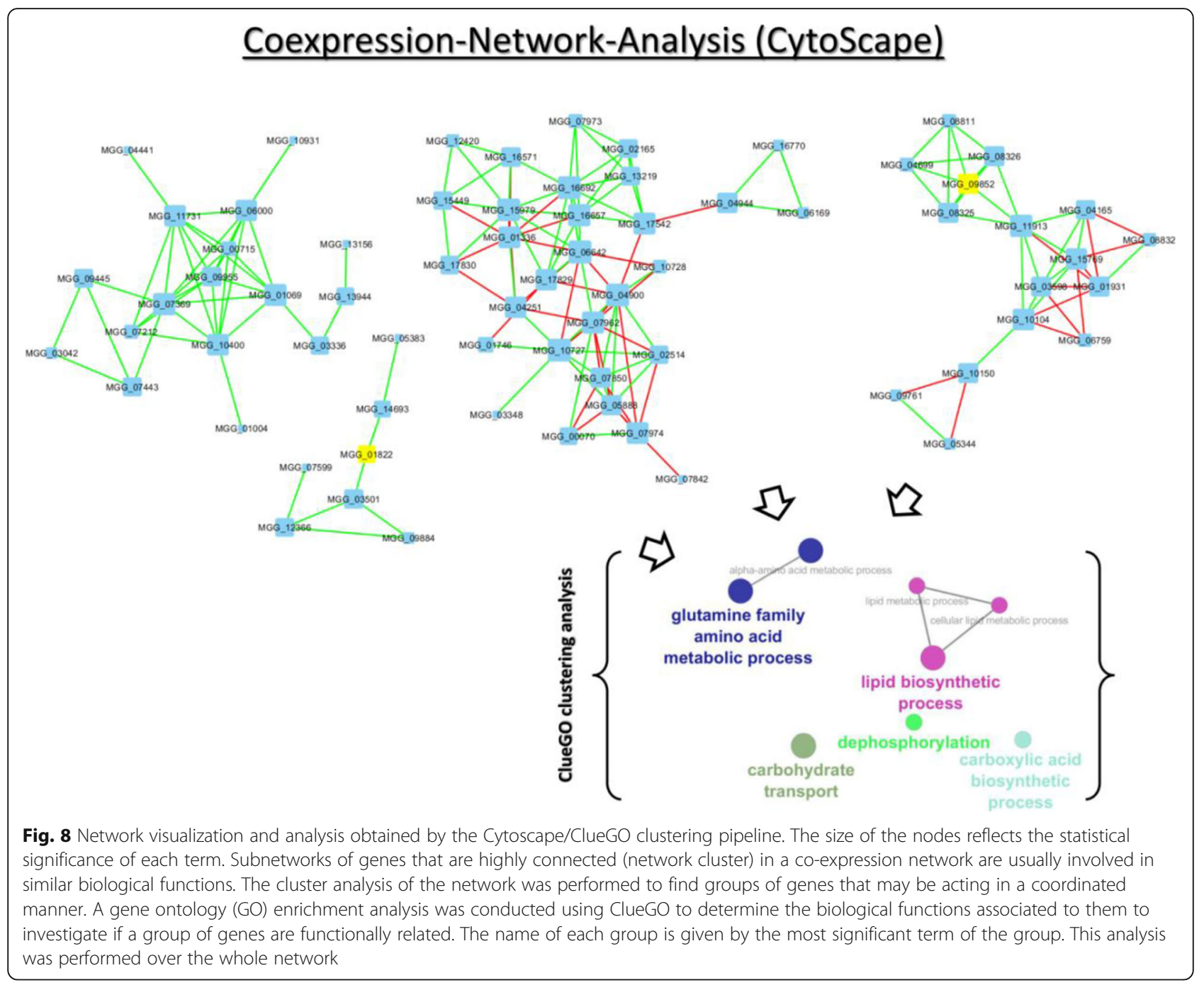

(MoGpd1p)) and one phosphatidyl synthase (MGG_ 00099 (MoHad1p)).

\section{The HOG pathway is not responsible for adaptation in $\triangle$ Mohog1(adapted)}

We searched for possible interactions between MoHog1p and other osmotic stress responsive or associative gene products using the SMART website to find links between putative interaction partners of the MAPK MoHog1p in the adapted strains. The genes identified were finally used to inspect their expression patterns within our set of DE genes (STRING analysis, Fig. 9a).

As expected, the transcript level of the responsive genes belonging to HOG pathway were found to be highly upregulated in case of the wildtype strain in response to osmotic stress (Fig. 9b). Thus, among the genes with the most abundant transcripts were MGG_ 01822, MGG_08212 and MGG_08547 encoding HOG1, a BZIP transcription factor and CAMK1 kinase, respectively (Fig. 9b, c. Meanwhile, none of the HOG1- associated genes, except for MGG_06759 encoding a heat shock protein, were transcriptionally active in $\triangle M o$ hog1 and in $\Delta$ Mohog1(adapted) (Fig. 9b). These results have been validated by means of qPCR (Additional file 7: Figure S6). That leads to the conclusion that other mechanisms operating independently/outside of the HOG pathway may be responsible for the phenotype observed in the adapted strains.

\section{Discussion}

A central focus in biology is evolution and understanding the processes facilitating or preventing it. Research in this field has to integrate information at the organism level with the sequence level, transcriptional control, epigenetic modulation or cellular differentiation [3]. Despite their complexity, biological networks have an inherent similarity: They are modular with a design that can be separated into single units which perform almost independently. Little is known about the evolutionary origin of these properties. It is of great interest to better 
Table 1 Glycerol biosynthesis and osmotic stress response-related genes being differentially expressed across the strains analyzed

\begin{tabular}{|c|c|c|c|c|c|c|}
\hline $\begin{array}{l}\text { MGG-number } \\
\text { (gene name) }\end{array}$ & $\begin{array}{c}\text { WT 70-15 } \\
\text { (Omin) }\end{array}$ & $\begin{array}{l}\text { WT 70-15 } \\
\text { (25min) }\end{array}$ & $\begin{array}{c}\Delta \text { Mohog1 } \\
\text { (Omin) }\end{array}$ & $\begin{array}{c}\Delta \text { Mohog1 } \\
\text { (25min) }\end{array}$ & $\begin{array}{c}\Delta \text { Mohog1 (adapted) } \\
\text { (Omin) }\end{array}$ & $\begin{array}{c}\Delta \text { Mohog1 (adapted) } \\
\text { (25min) }\end{array}$ \\
\hline MGG_01084 & 2151.02 & 2022.33 & 1794.08 & 1760.48 & 1786.37 & 1882.49 glyceraldehyde-3-phosphate dehydrogenase \\
\hline MGG_05880 & 875.76 & 113.15 & 221.3 & 43.5 & 594.04 & 51.43 aquaporin-9 [Verticillium alfalfae ] \\
\hline MGG_06759 & 792.62 & 220.57 & 815.04 & 327.68 & 1385.65 & 321.77 heat shock 90 \\
\hline MGG_06669 & 645.36 & 542.68 & 712.63 & 666.35 & 927.97 & 742.09 Hsp90 binding co-chaperone Sba1 \\
\hline MGG_00099 & 615.25 & 2953.14 & 34.02 & 97.1 & 52.03 & 362.34 phosphatidyl synthase \\
\hline MGG_11794 & 252.47 & 255.77 & 284.06 & 326.06 & 178.4 & 199.52 D-3-phosphoglycerate dehydrogenase 2 \\
\hline MGG_08180 & 203.97 & 156.76 & 109.65 & 48.97 & 302.63 & $46.88 \mathrm{psi} 1$ \\
\hline MGG_01822 & 178.49 & 1046.29 & 16.88 & 18.12 & 15.82 & 12.68 CMGC MAPK P38 kinase [Fusarium verticillioides 7600 ] \\
\hline MGG_00901 & 169.7 & 218.61 & 159.23 & 171.49 & 195.85 & 262.55 2,3-bisphosphoglycerate-independent phosphoglycerate mutase \\
\hline MGG_04960 & 145.08 & 170.69 & 103.98 & 121.12 & 53 & 88.9 phosphoglycerate mutase \\
\hline MGG_07527 & 117.6 & 75.91 & 107.41 & 66.47 & 71.77 & 45.79 imidazoleglycerol-phosphate dehydratase \\
\hline MGG_00067 & 95.81 & 162.76 & 49.33 & 39.49 & 78.9 & 80.55 glycerol-3-phosphate dehydrogenase \\
\hline MGG_03147 & 78.27 & 74.67 & 62.83 & 35.91 & 41.41 & 64.12 glycerol-3-phosphate dehydrogenase \\
\hline MGG_06642 & 64.81 & 51.57 & 14.08 & 11.33 & 72.42 & 54.55 phosphoglycerate mutase family domain-containing \\
\hline MGG_03320 & 62.35 & 45.32 & 74.62 & 78.3 & 83.04 & 98.32 AP-1 complex subunit beta-1 [Magnaporthe oryzae 70-15] \\
\hline MGG_04437 & 58.97 & 20 & 38.68 & 19.61 & 113.38 & 35.93 Heat shock mitochondrial \\
\hline MGG_07528 & 57.46 & 56.39 & 100.62 & 122.56 & 165.21 & 113.91 imidazoleglycerol-phosphate dehydratase \\
\hline MGG_02967 & 33.98 & 41.06 & 15.61 & 21.15 & 4.7 & 9.6 phosphoglycerate mutase \\
\hline MGG_00503 & 23.44 & 57.01 & 9.72 & 9.02 & 7.81 & 10.27 diacylglycerol O-acyltransferase [Magnaporthe oryzae 70-15] \\
\hline MGG_03550 & 13 & 123.79 & 13.04 & 14.5 & 7.53 & 11.98 CDP-diacylglycerol-serine 0-phosphatidyltransferase \\
\hline MGG_08047 & 10.09 & 16.47 & 17.19 & 29.32 & 10.24 & 42.95 glycerophosphoryl diester phosphodiesterase \\
\hline MGG_14825 & 9.85 & 6.88 & 11.68 & 27.91 & 17.43 & 36 osmostress-responsive transcription \\
\hline MGG_09852 & 8.12 & 1095.11 & 4.18 & 22.88 & 10.6 & 265.85 sugar transporter STL1 \\
\hline MGG_13527 & 2.65 & 3.39 & 14.83 & 19.86 & 9.31 & 7.56 suppressor of glycerol defect 1 \\
\hline
\end{tabular}

The table shows the glycerol biosynthesis and osmotic stress response-related genes retrieved being differentially expressed across the strains analyzed. The colors used in the table indicate the percentiles projected on the entire amounts of the transcripts counted (green stands for $90 \%$, white for $50 \%$ and red for $10 \%)$

understand how signaling pathways can be modified to generate new biochemical reactions or new morphologies [30].. How are new components integrated into existing signaling pathways and how evolve the pathways themselves? For example, a genome sequence analysis in yeast has identified healthy individuals even though carrying disease-related mutations. A second genomic mutation that can compensate for the detrimental effects of the disease allele may serve as possible explanation, that phenomenon is known as suppression [31]. Most of such suppression interactions are reported between genes that are annotated to the same biological process and thus have related functions [32-34]. This means that suppression appears to be caused by mutations in genes that are functionally similar to the query [8]. Suppression interactions are generally subdivided into two classes: Genomic suppressors and dosage suppressors. The first ones are mutations in the genome that bypass a mutant phenotype, and in the second ones, alteration of gene expression such as overexpression of a suppressor gene rescues a mutant phenotype [31]. Within this study, we found a suitable system to study rapid evolutionary adaptation processes in eukaryotic microorganisms, more exactly in fungal individuals. The physiological role of the HOG pathway is to orchestrate the adaptation of cells to increased osmolarity of the surrounding medium [35]. The lof mutants $\Delta$ Mohog1, $\Delta$ Mopbs2, $\Delta$ Mossk2, $\Delta$ Mossk 1 and $\Delta$ Moypd 1 in $M$. oryzae are strongly impaired in osmoregulation and are resistant to the fungicide fludioxonil [21]. We present that long-term cultivation upon high osmolarity resulted in stable individuals being restored in osmoregulation outgrowing from each of these lof mutants. Interestingly, the major compatible solute produced by these adapted strains upon salt stress is glycerol, whereas it is known to be arabitol in the wildtype strain (Fig. 4). In order to unravel this phenomenon, DNA- and RNA-Seq analysis was performed in the adapted strains compared to their lof-parent strains. The structural variation discovery analysis leading to protein effect (such as frameshift, stop codon insertion) resulted in only transitions not changing the amino acid composition of the corresponding proteins. Structural variations observed on the genomic landscape may generally have an impact (negative or positive) on the gene expression, which, in turn, may explain the adaptive phenotype observed. We have to distinguish between structural genomic variations seen in exons or CDS and those located in the regulatory elements of the genes (such as promoters, enhancers and terminators). The latter may cause variations in the gene expression, which necessitates the comparative analysis of SNV analysis data with RNA-Seq data (DEGs). On the other hand, the SNV located in CDS and exons is not expected to be reflected in the DEG. The encoded products may have an impact on the secondary and tertiary structure, caused by amino acid replacements, which may lead to reduced or, in some cases, enhanced functionality of the enzyme/protein. We have not been able to identify structural genomic variations in the regulatory elements of the genes so far (Additional file 6: Figure S5 [A]). Of course, we have to increase the number of adapted strains from which we will sequence the genomes to get a higher amount of reliable data to analyze genomic changes in more detail. On 


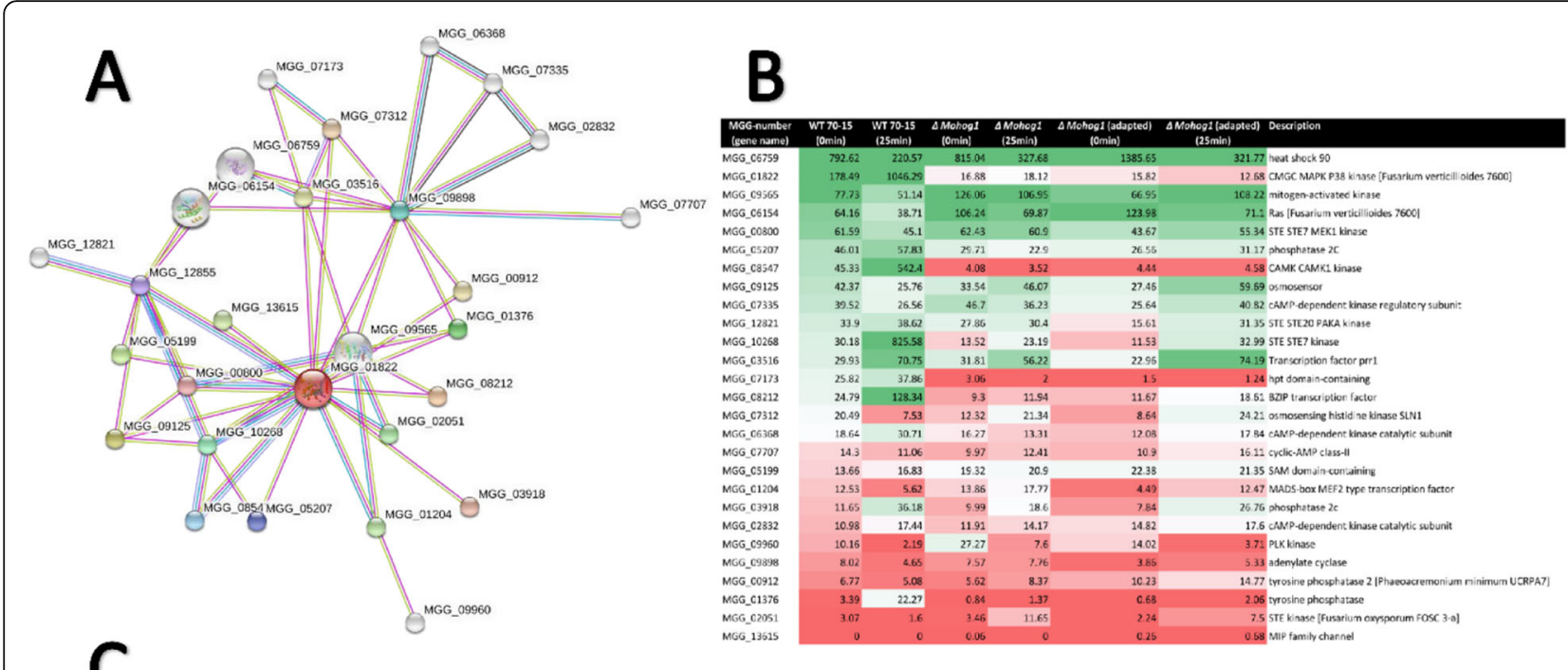

C
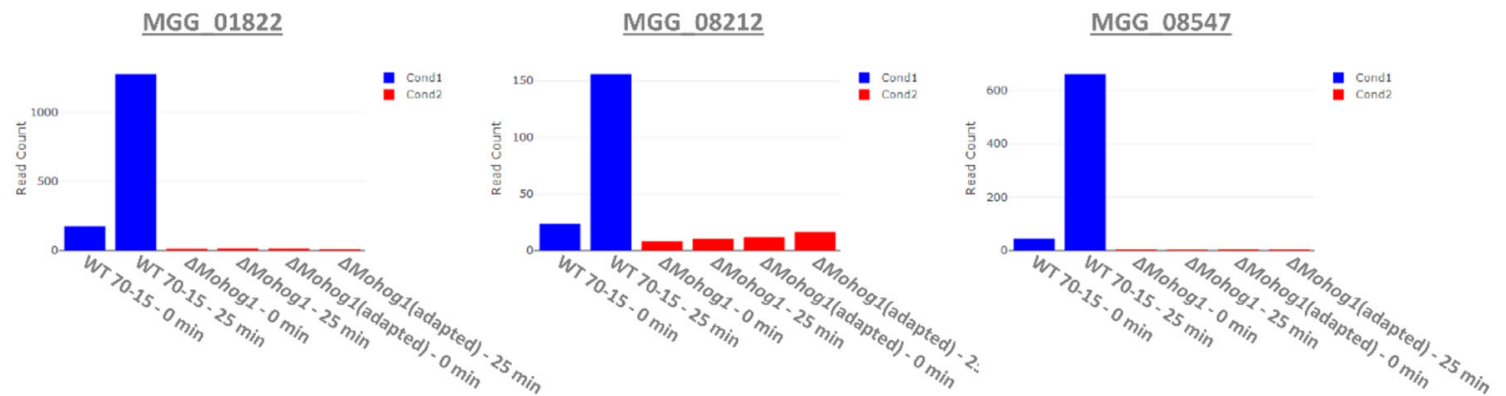

Fig. 9 Interaction network analyzed by the STRING website and gene expression profiles of HOG 1-related genes across the strains analyzed in this study. a STRING network visualization showing 30 proteins known to interact with Hog $1 p$ in yeast. With a confidence cutoff of 0.9 , the resulting network contains 48 functional associations between 30 of the proteins. $\mathbf{b}$ Expression profiles of DE genes obtained from the STRING analysis across the strains analyzed. $\mathbf{c}$ Expression profiles of candidate genes derived from the transcriptome analysis of the strains selected

transcriptome-level of the adapted strains, the interaction network conducted by SMART analysis revealed that none of the HOG1-associated genes, except for one heat shock protein, were transcriptionally active after salt stress in $\Delta$ Mohog1 and $\Delta$ Mohog1(adapted) in contrast to the MoWT (Fig. 9). This leads to the conclusion that other mechanisms operating independently of the HOG pathway may be responsible for the phenotype observed in the adapted strains. We found that set of candidate genes potentially contributing to the production, metabolism or transport of glycerol, which is significantly upregulated after salt stress in $\Delta$ Mohog1(adapted) and the wildtype strain, whereas these genes were not regulated in the lof mutant $\Delta$ Mohog1 (Table 1). These results fit well to the increased production of the compatible solute glycerol in the adapted strains in response to salt stress (Fig. 4). The phenomenon of the adapted strains $\Delta M o h o g 1$ (adapted), $\Delta M o p b s 2$ (adapted), $\Delta M o s s-$ k2(adapted), $\Delta$ Mossk1(adapted) and $\Delta$ Moypd1(adapted) is different to the yeast suppressor mutants regarding the genes RSG1 (RHB1) [25], SOO1 [26], SGD1 [27] and
PMK1 (KSS1) [28]. Exemplarily, some Hog1p-dependent osmotic stress-induced gene expression patterns in $S$. cerevisiae $\Delta$ hog1 mutants could be synthetically rewired under the control of Fus3p/Kss1p MAPKs (PMK1 homologues) [36]. Furthermore, alteration of only one amino acid in Kss1p suppresses the osmosensitive growth phenotype of the $\Delta$ hog1 deletion mutant [28]. Moreover, it is known that overexpression of the GPD1gene partly rescued the osmosensitive phenotype [37] and the gene SOO1 complements the temperaturedependent osmosensitivity of $\Delta$ hog1 [26]. Overexpression of $S G D 1$ partially suppresses the osmosensitivity of $\Delta p b s 2$ and $\Delta h o g 1$ mutants [27]. In conclusion, the loss of one gene may be compensated by another gene with overlapping functions and expression patterns, as reported for several mutants in a range of model organisms [38]. Thus, disorder of a particular gene's function in a network may alter the expression of other genes within the same network, thereby maintaining cellular homeostasis $[9,39]$. Gene deletion in yeast may result in mutations in one or more genes modulating the pathway 
affected, thereby, partially or fully rescuing the final outcome [40]. However, all of the statements above are based on results found by using the tractable yeast knockout collection and analysis thereof [40], and all findings have only been made in mapping and interpreting the growth rate as a proxy for fitness [8]. By contrast, the current study has the potential to open the door for many research groups worldwide working on the HOG pathway in different eukaryotic model organisms to study epigenetic and evolutionary adaptation mechanisms from a different point of view. It is of the highest scientific interest to obtain such adapted strains in other model organisms apart from $M$. oryzae. The yeasts $S$. cerevisiae and Schizosaccharomyces pombe [41] are, for example, model organisms from which to acquire adapted strains from HOG pathway lof mutants. Further candidates will be the opportunistic human fungal pathogens Candida albicans [42], Aspergillus fumigatus [43] or the basidiomycetous human fungal pathogen Cryptococcus neoformans [44]. The ascomycetes Aspergillus nidulans [45, 46], Botrytis cinerea [47], Fusarium graminearum [48] and Neurospora crassa [49], or even the plant pathogenic basidiomycete Ustilago maydis [50] will also be promising candidates, since the HOG pathway has been studied intensively in all of these fungi.

\section{Conclusion}

We found the filamentous rice blast fungus Magnaporthe oryzae to rapidly reestablish signal transduction required for osmoregulation in independent osmosensitive "loss-of-function" (lof)-mutants of the High Osmolarity Glycerol (HOG)-pathway upon exposure to salt stress. Adaptation resulted in stable mutants of the model organism being reestablished in osmoregulation arising as individuals outgrowing from the salt-sensitive mutants. These findings lead to the hypothesis that stable adaptation-events under continuously environmental evolutionary pressure enable Magnaporthe oryzae to rapidly restore or modify entire signaling networks.

This study provides evidence, that $M$. oryzae is a suitable model organism to study rapid evolutionary processes in eukaryotes. Furthermore, it will open a door for the scientific community to study this topic since the HOG pathway is worked on intensively in many different eukaryotic model organisms.

\section{Methods}

All data generated or analyzed during this study are included in this published article or deposited at the NCBI GenBank SRA database under accession number PRJNA559166 and Bioproject number 559166.

\section{Strains, culture/growth conditions}

The fungal strain used in this study was Magnaporthe oryzae (M. oryzae 70-15 strain (MoWT), Fungal Genetics Stock Center (FGSC)) and the lof mutants of the HOG pathway generated previously [21]. The strains were grown at $26^{\circ} \mathrm{C}$ on $\mathrm{CM}(\mathrm{pH} 6.5,2 \%$ agar, containing per liter: $10 \mathrm{~g}$ glucose, $1 \mathrm{~g}$ yeast extract, $2 \mathrm{~g}$ peptone, $1 \mathrm{~g}$ casamino acids, $50 \mathrm{~mL}$ nitrate salt solution (containing per liter: $120 \mathrm{~g} \mathrm{NaNO}_{3}, 10.4 \mathrm{~g} \mathrm{KCl}, 30.4 \mathrm{~g} \mathrm{KH}_{2} \mathrm{PO}_{4}, 10.4$ $\left.\mathrm{g} \mathrm{MgSO}_{4} \times 7 \mathrm{H}_{2} \mathrm{O}\right)$ and $1 \mathrm{~mL}$ of a trace element solution (containing per liter: $22 \mathrm{~g} \mathrm{ZnSO}_{4} \times 7 \mathrm{H}_{2} \mathrm{O}, 11 \mathrm{~g} \mathrm{H}_{3} \mathrm{BO}_{3}$, $5 \mathrm{~g} \mathrm{MnCl}_{2} \times 4 \mathrm{H}_{2} \mathrm{O}, 5 \mathrm{~g} \mathrm{FeSO}_{4} \times 7 \mathrm{H}_{2} \mathrm{O}, 1.7 \mathrm{~g} \mathrm{CoCl}_{2} \times 6$ $\mathrm{H}_{2} \mathrm{O}, 1.6 \mathrm{~g} \mathrm{CuSO}_{4} \times 5 \mathrm{H}_{2} \mathrm{O}, 1.5 \mathrm{~g} \mathrm{Na}_{2} \mathrm{MoO}_{4} \times 2 \mathrm{H}_{2} \mathrm{O}, 50$ g $\mathrm{Na}_{2}$ EDTA, pH 6.5 adjusted by $\left.1 \mathrm{M} \mathrm{KOH}\right)$. The MM (pH 6.5) contains per liter: $1 \mathrm{~g}$ glucose, $0.25 \mathrm{~mL}$ of a $0.01 \%$ biotin solution, $50 \mathrm{~mL}$ nitrate salt solution, $1 \mathrm{~mL}$ of a trace element solution and $1 \mathrm{~mL}$ of a $1 \%$ thiamine dichloride solution.

All chemicals used were p.a. quality unless stated otherwise.

\section{Vegetative growth assays}

The antifungal activity and stress tolerance of vegetative growth on agar plates were conducted according to [24]. In order to verify the results, we determined the mycelium dry weight of the fungal colonies grown in liquid culture. The fungal colonies were grown in $250 \mathrm{ml} \mathrm{CM}$ including sorbitol or $\mathrm{KCl}$ for $6 \mathrm{~d}$ at $26^{\circ} \mathrm{C}$ and $120 \mathrm{rpm}$.

\section{Empirical investigation of the "adaptation" frequency}

In order to determine the adaptation in $M$. oryzae, we conducted a combination of different vegetative growth assays to generate adapted mutant strains to characterize the "adaption frequency." We used a panel of 11-day-old lof mutant strains of each of $\Delta$ Mohog1, $\Delta M o p b s 2$, $\Delta$ Mossk2, $\Delta$ Mossk1, $\Delta$ Moypd1, $\Delta M o h i k 1$ and $\Delta M o s \ln 1$ to inoculate solid $\mathrm{CM}$ including $1 \mathrm{M} \mathrm{KCl}$ or $1.5 \mathrm{M}$ sorbitol as stress-inducers. The most suitable concentration ranges of the individually selected stressors was chosen based on our previous work in the osmoregulation pathway $[21,24]$ : The mutants should be clearly restricted in growth but still being able to grow. All fungal cultures have been incubated at $26^{\circ} \mathrm{C}$ and a light/dark rhythm of $16 / 8 \mathrm{~h}$ and have been regularly transferred to fresh medium. After 8-12 weeks, we selected all outgrowing mycelium parts (individuals) from this experimental setup and put them on normal CM without stressors for the following two weeks. We then put the colonies on repeated stress medium to investigate in which strains the "adaptation" is stable.

\section{Plant infection assays}

The plant infection assays were carried out as described previously [24]. 


\section{HPAEC-PAD analysis to quantify compatible solute production}

Osmolytes (sugar alcohols, monosaccharides and disaccharides) were analyzed using HPAEC. They were separated as anions under high alkaline conditions $(\mathrm{pH}>12)$, coupled with PAD. Dried cell extracts were solved (sonificated) in 1 $\mathrm{ml}$ sterilized, double-distilled water and centrifuged $\left(4^{\circ} \mathrm{C}\right.$, $13,000 \mathrm{rpm})$. All the samples were filtrated through a $0.2 \mu \mathrm{m}$ filter. The injection volume was $10 \mu \mathrm{l}$. The HPAECPAD analysis was performed on a Shimadzu LC system equipped with two LC-10Ai pumps, a DGU-20A degassing unit, a SIL-10Ai autosampler, a CBM-20A controller and a CTO-20 AC column oven. An analysis anion-exchange column of CarboPac MA1 $(4 \times 250 \mathrm{~mm})$ in combination with a guard column of CarboPac MA1 $(4 \times 50 \mathrm{~mm})$ at $20^{\circ} \mathrm{C}$ was used. A Dionex ED40 Electrochemical detector was used for the detection of carbohydrates and sugar alcohols in pulsed amperometric mode through standard quadruple waveform $(\mathrm{t}=0-0.40 \mathrm{~s}, p=1.00 \mathrm{~V} ; \mathrm{t}=0.41-0.42 \mathrm{~s}, p=-$ $2.00 \mathrm{~V} ; \mathrm{t}=0.43 \mathrm{~s}, p=6.00 \mathrm{~V} ; \mathrm{t}=0.44-0.50 \mathrm{~s}, p=-1.00 \mathrm{~V})$. The eluent was prepared as a mobile phase which consisted of a $480 \mathrm{mM} \mathrm{NaOH}$ solution. Isocratic elution was performed at $0.4 \mathrm{ml} / \mathrm{min}$. Aqueous sodium hydroxide $(50 \%$, w/ w) was obtained from Merck, Germany. Standards were purchased from Sigma-Aldrich (Germany) and Carl Roth (Germany). Solutions were prepared in double-distilled water with a concentration of $10 \mathrm{mg} / \mathrm{L}$.

\section{Bioinformatics and data visualization}

The DEBrowser recently published was used for data assessment. Firstly, the filtering of the genes was performed. The maximum count for each gene across all samples less than a threshold set to 10 was chosen as the filtering criterium. The application provides a rich and interactive web-based graphical user interface built on R's shiny infrastructure. The novel method, called "Median Ratio Normalization," which provides the lower number of false discoveries was used for the normalization of data prior to processing to heat maps and other plots.

The interactive heat map was generated using Clustergrammer [51] which is freely available at http://amp. pharm.mssm.edu/clustergrammer/. Clustergrammer is a web-based tool for visualizing and analyzing highdimensional data as interactive and hierarchically clustered heat maps. It is commonly used to explore the similarity between samples in an RNA-Seq dataset. In addition to identifying clusters of samples, it also allows one to identify the genes which contribute to the clustering. Prior to displaying the heat map, the raw gene counts were normalized using the $\log$ CPM method, filtered by selecting the 500 genes with the most variable expression and, finally, transformed using the Z-score method.

\section{Transcriptome sequencing and differential gene expression}

Transcriptome differences in response to salt stress were determined by RNA-Seq using next-generation sequencing. Consequently, the RNA of the strains $M$. oryzae 70-15, $\Delta$ Mohog1 and $\Delta$ Mohog1(adapted) was isolated using the RNeasy ${ }^{\oplus}$ Plant Mini Kit (Qiagen). Two conditions were analyzed: Prior salt stress $(0 \mathrm{~min})$ and salt stress incubation after $25 \mathrm{~min}$. We collected $M$. oryzae samples for the transcriptome sequencing from two different growing conditions and used three replicates each: At 0 and $25 \mathrm{~min}$.

The RNA isolated was subsequently quantified using the 2100 Bioanalyzer High Sensitivity DNA kit (Agilent Technologies, Santa Clara, CA, USA) and sequenced in a $150 \mathrm{bp}$ paired-end run on an Illumina HiSeq 2500. Library preparation was performed by IMSB (Mainz, Germany) using $1.5 \mu \mathrm{g}$ of total RNA for each strain. The raw fastq reads were paired and aligned to a 70-15 strain reference sequence (assembly version MG8, http://fungi.ensembl.org/Magnaporthe_oryzae/Info/

Index) using default parameters with Geneious RNA Mapper (version 11.1.5).

The Integrative Genomics Viewer ( $[52,53])$ was then used to visualize the transcripts assembled. The DEGs were identified by the DEseq2 [54]. Genes with an adjustment of $p$-values by Benjamini Hochberg FDR $($ FDR $<0.05)$ and fold change values $>2.5$ were considered to be differentially expressed.

Considering the processed RNA-sequencing (Seq) data, a total of 684 differentially expressed genes (DEGs) (176 up- and 508 down-regulated) were identified in the WT $70-15$ vs. $\Delta$ Mohog1 $+\Delta$ Mohog1(adapted) comparison; while 49 DEGs (23 up- and 26 down-regulated) were identified in the WT 70-15+ Mohog1(adapted) vs. $\Delta M \operatorname{ohog} 1$ comparison. Meanwhile, a total of 16 DEGs (9 up- and 7 down-regulated) were present in the WT 70-15 (untreated) $+\Delta M o h o g 1$ (untreated $)+\Delta M o h o g 1(a-$ dapted) (untreated) vs. WT 70-15 (25 min 0.5 M KCLstress $)+\Delta$ Mohog1 (25 min 0.5 M KCL-stress $)+\Delta M o h o-$ g1(adapted) (25 min 0.5 M KCL-stress) comparison.

\section{RNA isolation, CDNA amplification and qRT-PCR analysis}

We conducted a qPCR analysis of selected genes previously found to be strong regulated in our RNA-seq results for validation of the datasets. The $M$. oryzae cultures were grown for $96 \mathrm{~h}$ in $\mathrm{CM}$ at $26^{\circ} \mathrm{C}$ and 100 $\mathrm{rpm}$. Each of the cultures were separated into two samples, one mixed with $0.5 \mathrm{M} \mathrm{KCl}$ and one an untreated control. Samples for RNA isolation were taken after 25 min. The RNA was isolated from the mycelium samples and the results of transcript abundance given relative to quantification in the MoWT untreated control. The RNA of the MoWT and the mutants was isolated 
according to [29] using a RNeasy plant mini Kit (Quiagen $\mathrm{GmbH}$ ), following the manufacturer's instructions for purification of total RNA from plants and filamentous fungi. The cDNA amplification and qRT-PCR were performed using the iScript ${ }^{\text {tw }}$ One-Step RT-PCR Kit with SYBR $^{\circ}$ Green (Bio-Rad Laboratories $\mathrm{GmbH}$ ), following the manufacturer's instructions. We used the tubulin gene (MGG_06650) and the EF1-alpha gene (MGG MGG_03641) as reference genes (housekeeping genes) for the relative quantification of the expression ratio. Calculations were based on the relative quantification method of [55].

\section{SNP analysis}

Sequencing reads mapped against the 70-15 reference genome (as .bam files) were used to detect structural genomic variants. Both SNVs and short indels were detected for all strains in comparison with the reference sequence of 70-15. We used the Genome Analysis ToolKit pipeline for SNP calling. The alignment (.bam) files were manually visualized by the Integrative Genomics Viewer to identify commonly associated SNPs. We used VarScan 2 and Pindel for the detection of small indels [56]. We used Pindel for large indels and structural variations as it is described as working well on variations between 1 and $1000 \mathrm{nt}$. BreakDancer-predicted variants were filtered based on mapping quality greater than 25 read, read depths greater than 10 and strand level evidence (at least one read from both directions). SnpEff software was employed to analyze and annotate the resulting SNPs with the $M$. oryzae sequence and the GFF annotation file (MG8, http://fungi.ensembl.org/ Magnaporthe_oryzae/Info/Index) in terms of their chromosomal location and biological effects, such as synonymous/non-snonymous SNPSs, UTRs, intergenic or upstream/downstream.

\section{Supplementary information}

Supplementary information accompanies this paper at https://doi.org/10. 1186/s12864-019-6113-3.

Additional file 1: SVs summary.

Additional file 2: Figure S1. Schematic presentation and verification of the MoWT, the lof-mutants and the adapted strains by southern hybridization within the Magnaporthe oryzae genome. Southern blot analysis of gene deletion/disruption mutants in M. oryzae with gene specific probes. Genomic DNA of M. oryzae strain 70-15 and the mutants was isolated and restricted with restriction enzymes. The probes which we used for hybridization with the genomic DNA of the wildtype strain and the corresponding mutant strains were always identical.

Additional file 3: Figure S2. Investigation of the "adaptation-frequency" in Magnaporthe oryzae mutants with inactivated components of the HOG signaling cascade.

Additional file 4: Figure S3. Mycelium dry weight of the Magnaporthe oryzae wildtype strain, mutants with inactivated components of the HOG signaling cascade and the "adapted" strains after growth in liquid culture upon sorbitol-stress. The fungal colonies were grown in $250 \mathrm{ml}$ complete medium inclusive $1,5 \mathrm{M}$ sorbitol for $6 \mathrm{~d}$ at $26^{\circ} \mathrm{C}$ and $120 \mathrm{rpm}$. Error bars represent the standard deviation of three biological replicates of each strain.

Additional file 5: Figure S4. Pathogenicity assay of the MoWT, the lof mutants and the "adapted" strains. The plant infection assays were carried out as described in experimental procedures. The error bars represent the standard deviation of three experiments with three replicates each.

Additional file 6: Figure S5. VENN diagram of putative structural variations in promotor $[A]$ and in coding sequences (CDS) $[B]$ within the genome of $\Delta$ Mohog1, $\Delta$ Mohogl (adapted) and $\Delta$ Mopbs2(adapted). Numbers in the intersection regions represent overlapping SNPs among the strains. Numbers in parentheses show the corresponding relative percentage of genes harbouring the SNPS.

Additional file 7: Figure S6. QPCR results of selected genes. QRT-PCR analysis of putative genes in MoWT, the "lof" mutants $\Delta$ Mohog1 and $\Delta$ Mohog1 (adapted). The M. oryzae cultures were grown for $96 \mathrm{~h}$ in $\mathrm{CM}$ at $26^{\circ} \mathrm{C}$ and $100 \mathrm{rpm}$. Each of the cultures was separated into two samples, one mixed with $0.5 \mathrm{M} \mathrm{KCl}$ and one untreated control further grown in $\mathrm{CM}$ at $26^{\circ} \mathrm{C}$ and $\left.100 \mathrm{rpm}\right)$. Samples were taken after $25 \mathrm{~min}$. The RNA was isolated from the mycelium samples and the results of transcript abundance given relative to quantification in the MoWT untreated control. Three biological replicates were used of each.

\section{Abbreviations}

CM: Complete medium; DEGs: Differentially expressed genes; ERK: Extracellular signal-regulated kinase; GO: Gene ontology; HK: twocomponent hybrid histidine kinase; HOG: High osmolarity glycerol; HPAECPAD: High-performance anion-exchange chromatography with pulsed amperometric detection; lof: "Loss of function"; MAPK: Mitogen-activated protein kinase; MAPKK: MAPK kinase; MAPKKK: MAPK kinase kinase; MM: Minimal medium; PCs: Principal components; SNPs: Single-nucleotide polymorphisms; SNVs: Single nucleotide variations; UTRs: untranslated regions; WT 70-15: Magnaporthe oryzae wildtype strain

\section{Acknowledgements}

Not applicable

\section{Authors' contributions}

SB: acquisition, analysis and interpretation of the data; conception and design; writing. LA: analysis of the data; conception, design and design of analytic methods. CG: analysis of the data; conception and design of analytic methods. AY: analysis and interpretation of the sequencing data; conception and design of bioinformatics data. KA: analysis and interpretation of the sequencing data. SJ: acquisition, analysis and interpretation of the data; conception and design; writing. All authors have read and approved the manuscript.

\section{Funding}

The study was supported by the DFG focus program 1819 (Grant no. JA2632/3-1; project no. 403841309; awarded to SJ).

\section{Availability of data and materials}

All data generated or analyzed during this study are included in this published article or deposited at the NCBI GenBank SRA database under accession number PRJNA559166 and Bioproject number 559166.

Ethics approval and consent to participate

Not applicable

Consent for publication

Not applicable

\section{Competing interests}

The authors declare that they have no competing interests. 
Received: 19 March 2019 Accepted: 20 September 2019

Published online: 22 October 2019

\section{References}

1. Gresham D, Desai MM, Tucker CM, Jenq HT, Pai DA, Ward A, et al. The Repertoire and Dynamics of Evolutionary Adaptations to Controlled Nutrient-Limited Environments in Yeast. Snyder M, editor. PLoS Genet. 2008; 4(12):e1000303. [cited 2019 Jan 10]. Available from: https://doi.org/10.1371/ journal.pgen.1000303

2. Good BH, McDonald MJ, Barrick JE, Lenski RE, Desai MM. The dynamics of molecular evolution over 60,000 generations. Nature. $2017 ; 551$ (7678):45-50 [cited 2019 Jan 9]. Available from: http://www.nature.com/doifinder/10.103 $8 /$ nature24287

3. Soyer OS, Bonhoeffer S. Evolution of complexity in signaling pathways. Proc Natl Acad Sci U S A [Internet]. 2006;103(44):16337-16342. [cited 2018 Nov 14]. Available from: http://www.ncbi.nlm.nih.gov/pubmed/17060629.

4. Gordley RM, Bugaj LJ, Lim WA. Modular engineering of cellular signaling proteins and networks. Curr Opin Struct Biol. 2016;39:106-14.

5. Lees JG, Dawson NL, Sillitoe I, Orengo CA. Functional innovation from changes in protein domains and their combinations. Curr Opin Struct Biol. 2016;38:44-52

6. Szyf M. Nongenetic inheritance and transgenerational epigenetics. Trends Mol Med. 2015;21(2):134-144. [cited 2019 Jan 29]. Available from: https:// www.sciencedirect.com/science/article/pii/S1471491414002184

7. Barrick JE, Lenski RE. Genome dynamics during experimental evolution. Nat Rev Genet. 2013;14(12):827-839. [cited 2017 Feb 10]. Available from: http:// www.nature.com/doifinder/10.1038/nrg3564

8. van Leeuwen J, Pons C, Mellor JC, Yamaguchi TN, Friesen $\mathrm{H}$, Koschwanez J, et al. Exploring genetic suppression interactions on a global scale. Science. 2016354(6312):aag0839. [cited 2018 Nov 14]. Available from: http://www. ncbi.nlm.nih.gov/pubmed/27811238.

9. Davidson E, Levin M. Gene regulatory networks. Proc Natl Acad Sci U S A. 2005;102(14):4935. [cited 2018 Sep 25]. Available from: http://www.ncbi.nlm. nih.gov/pubmed/15809445.

10. Pawson T, Nash P. Assembly of Cell Regulatory Systems Through Protein Interaction Domains. Science (80- ). 2003;300(5618)

11. Bhattacharyya RP, Reményi A, Yeh BJ, Lim WA. Domains, Motifs, and Scaffolds: The Role of Modular Interactions in the Evolution and Wiring of Cell Signaling Circuits. Annu Rev Biochem. 2006;75(1):655-680. [cited 2017 Jan 26]. Available from: http://www.annualreviews.org/doi/10.1146/annurev. biochem.75.103004.142710

12. Rubin GM. The draft sequences: Comparing species. Nature. 2001;409(6822): 820-821. [cited 2017 Jan 26]. Available from: http://www.nature.com/ doifinder/10.1038/35057277

13. Bornberg-Bauer E, Albà MM. Dynamics and adaptive benefits of modular protein evolution. Curr Opin Struct Biol. 2013;23(3):459-66.

14. Pawson T, Scott JD. Signaling Through Scaffold, Anchoring, and Adaptor Proteins. Science (80- ). 1997:278(5346).

15. Park S-H, Zarrinpar A, Lim WA. Rewiring MAP Kinase Pathways Using Alternative Scaffold Assembly Mechanisms. Science (80- ). 2003;299(5609).

16. Chen RE, Thorner J. Function and regulation in MAPK signaling pathways: lessons learned from the yeast Saccharomyces cerevisiae. Biochim Biophys Acta - Mol Cell Res. 2007;1773(8):1311-40

17. Hamel L-P, Nicole M-C, Duplessis S, Ellis BE. Mitogen-activated protein kinase signaling in plant-interacting fungi: distinct messages from conserved messengers. Plant Cell [Internet]. 2012;24(4):1327-1351. [cited 2018 Oct 2]. Available from: http://www.ncbi.nlm.nih.gov/pubmed/2251 7321

18. Xu JR, Hamer JE. MAP kinase and CAMP signaling regulate infection structure formation and pathogenic growth in the rice blast fungus Magnaporthe grisea. Genes Dev [Internet]. 1996;10(21):2696-2706. [cited 2017 Feb 2]. Available from: http://www.ncbi.nlm.nih.gov/pubmed/8946911.

19. $\mathrm{Xu} J \mathrm{R}$, Staiger $\mathrm{CJ}$, Hamer JE. Inactivation of the mitogen-activated protein kinase Mps1 from the rice blast fungus prevents penetration of host cells but allows activation of plant defense responses. Proc Natl Acad Sci U S A [Internet]. 1998;95(21):12713-12718. [cited 2017 Feb 2]. Available from: http:/www.ncbi.nlm.nih.gov/pubmed/9770551.

20. Dixon KP, Xu JR, Smirnoff N, Talbot NJ. Independent signaling pathways regulate cellular turgor during hyperosmotic stress and appressoriummediated plant infection by Magnaporthe grisea. Plant Cell [Internet]. 1999;
11(10):2045-2058. [cited 2017 Feb 2]. Available from: http://www.ncbi.nlm nih.gov/pubmed/10521531.

21. Jacob S, Foster AJ, Yemelin A, Thines E. High osmolarity glycerol (HOG) signalling in Magnaporthe oryzae: Identification of MoYPD1 and its role in osmoregulation, fungicide action, and pathogenicity. Fungal Biol [Internet]. 2015;119(7):580-594. [cited 2015 Mar 19]. Available from: http://linkinghub. elsevier.com/retrieve/pii/S1878614615000392

22. Jacob S, Schüffler $A$, Thines $E$. Hog $1 p$ activation by marasmic acid through inhibition of the histidine kinase SIn1p. Pest Manag Sci [Internet]. 2016;72(6): 1268-1274. [cited 2016 Apr 25]. Available from: http://doi.wiley.com/10.1 002/ps.4257

23. Bohnert $\mathrm{S}$, Neumann $H$, Thines $E$, Jacob $S$. Visualizing fungicide action: an in vivo tool for rapid validation of fungicides with target location HOG pathway. Pest Manag Sci [Internet]. 2018; [cited 2018 Oct 2]. Available from: http://doi.wiley.com/10.1002/ps.5177

24. Jacob S, Foster AJ, Yemelin A, Thines E. Histidine kinases mediate differentiation, stress response, and pathogenicity in Magnaporthe oryzae. Microbiologyopen [Internet]. 2014;3(5):668-687. [cited 2015 Mar 9]. Available from: http://doi.wiley.com/10.1002/mbo3.197

25. Prior BA, Hohmann S. Glycerol production and Osmoregulation. In: Yeast Sugar Metabolism [Internet]. Technomic Publishing Company; 1995 [cited 2019 Feb 14]. p. 313-33. Available from: https://books.google.de/books?hl=de\&lr=\&id= VSQZ1AVg74oC\&oi=fnd\&pg=PA313\&dq=hohmann+and+albertyn+1995+ rsg+1\&ots=Pmul9SdwMZ\&sig=OqxSrjHXNhiWDwyTljAcV9s7RhQ\#v= onepage\&q=hohmannandalbertyn1995rsg1\&f=false.

26. Lee D-W, Ahn G-W, Kang H-G, Park H-M. Identification of a gene, SOO1, which complements osmo-sensitivity and defect in in vitro B1,3-glucan synthase activity in Saccharomyces cerevisiae. Biochim Biophys Acta - Mol Cell Res [Internet]. 1999;1450(2):145-154. [cited 2018 Nov 14]. Available from: https://doi.org/10.1016/S0167-4889(99)00041-5

27. Akhtar N, Påhlman A-K, Larsson K, Corbett AH, Adler L. SGD1 encodes an essential nuclear protein of Saccharomyces cerevisiae that affects expression of the GPD1 gene for glycerol 3-phosphate dehydrogenase. FEBS Lett [Internet]. 2000:483(2-3):87-92. [cited 2018 Nov 15]. Available from: https:// doi.org/10.1016/S0014-5793(00)02087-1

28. Lee S-J, Park S-Y, Na J-G, Kim Y-J. Osmolarity hypersensitivity of hog1 deleted mutants is suppressed by mutation in KSS1 in budding yeast Saccharomyces cerevisiae. FEMS Microbiol Lett [Internet]. 2002;209(1):9-14. [cited 2018 Nov 15]. Available from: https://doi.org/10.1111/j.1574-6968. 2002.tb11102.x

29. Jacob S, Yemelin A, Bohnert S, Andresen K, Thines E. The exceptionality of stress response in Magnaporthe oryzae: a set of "salt stress-induced" genes unique to the rice blast fungus. J Plant Dis Prot [Internet]. 2017; 124(4):399-402 Available from: http://link.springer.com/10.1007/s41348-01 7-0074-z

30. Pires-da Silva A, Sommer RJ. The evolution of signalling pathways in animal development. Nat Rev Genet [Internet]. 2003:4(1):39-49. [cited 2018 Nov 14]. Available from: http://www.nature.com/articles/nrg977

31. van Leeuwen J, Pons C, Boone C, Andrews BJ. Mechanisms of suppression: The wiring of genetic resilience. BioEssays [Internet]. 2017;39(7):1700042. [cited 2018 Sep 25]. Available from: http://doi.wiley.com/10.1002/bies.201700042

32. Manson MD. Allele-Specific Suppression as a Tool to Study Protein-Protein Interactions in Bacteria. Methods [Internet]. 2000;20(1):18-34. [cited 2018 Nov 14]. Available from: https://www.sciencedirect.com/science/article/pii/ S1046202399909027?via\%3Dihub

33. Jorgensen EM, Mango SE. The art and design of genetic screens: Caenorhabditis elegans. Nat Rev Genet [Internet]. 2002;3(5):356-369. [cited 2018 Nov 14]. Available from: http://www.nature.com/articles/nrg794

34. Szamecz B, Boross G, Kalapis D, Kovács K, Fekete G, Farkas Z, et al. The Genomic Landscape of Compensatory Evolution. Barton NH, editor. PLoS Biol [Internet]. 2014;12(8):e1001935. [cited 2018 Nov 14]. Available from: https://dx.plos.org/10.1371/journal.pbio.1001935

35. Hohmann S. Control of high osmolarity signalling in the yeast Saccharomyces cerevisiae. FEBS Lett [Internet]. 2009;583(24):4025-4029. [cited 2018 Nov 15]. Available from: http://doi.wiley.com/10.1016/j. febslet.2009.10.069

36. Babazadeh R, Furukawa T, Hohmann S, Furukawa K, Widmann C, Gibson S, et al. Rewiring yeast osmostress signalling through the MAPK network reveals essential and non-essential roles of Hog 1 in osmoadaptation. Sci Rep [Internet]. 2014:4:143-180. [cited 2017 Jan 31]. Available from: http:// www.nature.com/articles/srep04697 
37. Albertyn J, Hohmann S, Thevelein JM, Prior BA. GPD1, which encodes glycerol-3-phosphate dehydrogenase, is essential for growth under osmotic stress in Saccharomyces cerevisiae, and its expression is regulated by the high-osmolarity glycerol response pathway. Mol Cell Biol [Internet]. 1994; 14(6):4135-4144. [cited 2017 Jan 31]. Available from: http://www.ncbi.nlm. nih.gov/pubmed/8196651.

38. El-Brolosy MA, Stainier DYR. Genetic compensation: A phenomenon in search of mechanisms. PLoS Genet [Internet]. 2017;13(7):e1006780. [cited 2018 Sep 25]. Available from: http://www.ncbi.nlm.nih.gov/pubmed/28704371.

39. Barabási A-L, Oltvai ZN. Network biology: understanding the cell's functional organization. Nat Rev Genet [Internet]. 2004;5(2):101-113. [cited 2018 Sep 25]. Available from: http://www.nature.com/articles/nrg1272

40. Teng X, Dayhoff-Brannigan M, Cheng W-C, Gilbert CE, Sing CN, Diny NL, et al. Genome-wide Consequences of Deleting Any Single Gene. Mol Cell [Internet]. $2013 ; 52(4): 485-494$. [cited 2018 Sep 25]. Available from: https:// www.sciencedirect.com/science/article/pii/S109727651300748X

41. Toone WM, Jones N. Stress-activated signalling pathways in yeast. Genes to Cells [Internet]. 1998;3(8):485-498. [cited 2019 Jan 16]. Available from: http:// doi.wiley.com/10.1046/j.1365-2443.1998.00211.x

42. Enjalbert B, Smith DA, Cornell MJ, Alam I, Nicholls S, Brown AJP, et al. Role of the Hog1 Stress-activated Protein Kinase in the Global Transcriptional Response to Stress in the Fungal Pathogen Candida albicans. Mol Biol Cell [Internet]. 2006;17(2):1018-1032. [cited 2019 Jan 16]. Available from: http:// www.molbiolcell.org/doi/10.1091/mbc.e05-06-0501

43. Ma D, Li R. Current Understanding of HOG-MAPK Pathway in Aspergillus fumigatus. Mycopathologia [Internet]. 2013;175(1-2):13-23. [cited 2019 Jan 16]. Available from: http://link.springer.com/10.1007/s11046-012-9600-5

44. Kojima K, Bahn Y-S, Heitman J. Calcineurin, Mpk1 and Hog1 MAPK pathways independently control fludioxonil antifungal sensitivity in Cryptococcus neoformans. Microbiology [Internet]. 2006;152(3):591-604. [cited 2019 Jan 16]. Available from: http://mic.microbiologyresearch.org/content/journal/ micro/10.1099/mic.0.28571-0

45. Hagiwara D, Asano Y, Marui J, Yoshimi A, Mizuno T, Abe K. Transcriptional profiling for Aspergillusnidulans HogA MAPK signaling pathway in response to fludioxonil and osmotic stress. Fungal Genet Biol [Internet]. 2009;46(11): 868-878. [cited 2019 Jan 16]. Available from: https://www.sciencedirect. com/science/article/pii/S1087184509001224

46. Kawasaki L, Sanchez O, Shiozaki K, Aguirre J. SakA MAP kinase is involved in stress signal transduction, sexual development and spore viability in Aspergillus nidulans. Mol Microbiol [Internet]. $2002 ; 45(4): 1153-1163$. [cited 2019 Jan 16]. Available from: http://doi.wiley.com/10.1046/j.1365-2958.2002. 03087.x

47. Segmüller N, Ellendorf U, Tudzynski B, Tudzynski P. BcSAK1, a stressactivated mitogen-activated protein kinase, is involved in vegetative differentiation and pathogenicity in Botrytis cinerea. Eukaryot Cell [Internet]. 2007;6(2):211-221. [cited 2019 Jan 16]. Available from: http://www.ncbi.nlm. nih.gov/pubmed/17189492

48. Zheng D, Zhang S, Zhou X, Wang C, Xiang P, Zheng Q, et al. The FgHOG1 Pathway Regulates Hyphal Growth, Stress Responses, and Plant Infection in Fusarium graminearum. Lee Y-W, editor. PLoS One [Internet]. $2012 ; 7(11)$ : e49495. [cited 2019 Jan 16]. Available from: https://dx.plos.org/10.1371/ journal.pone.0049495

49. Yamashita K, Shiozawa A, Watanabe S, Fukumori F, Kimura M, Fujimura M. ATF-1 transcription factor regulates the expression of ccg-1 and cat-1 genes in response to fludioxonil under OS-2 MAP kinase in Neurospora crassa. Fungal Genet Biol [Internet]. 2008;45(12):1562-1569. [cited 2019 Jan 16]. Available from: https://www.sciencedirect.com/science/article/pii/S10871845 0800203 X\#fig1.

50. Orth AB, Rzhetskaya M, Pell EJ, Tien M. A serine (threonine) protein kinase confers fungicide resistance in the phytopathogenic fungus Ustilago maydis. Appl Environ Microbiol [Internet]. 1995;61(6):2341-2345. [cited 2019 Jan 16]. Available from: http://www.ncbi.nlm.nih.gov/pubmed/7793954.

51. Fernandez NF, Gundersen GW, Rahman A, Grimes ML, Rikova K, Hornbeck P, et al. Clustergrammer, a web-based heatmap visualization and analysis tool for high-dimensional biological data. Sci Data [Internet]. 2017:4:170151. [cited 2018 Nov 16]. Available from: http://www.nature.com/articles/sdata2 017151

52. Robinson JT, Thorvaldsdóttir $H$, Winckler W, Guttman M, Lander ES, Getz $\mathrm{G}$, et al. Integrative genomics viewer. Nat Biotechnol [Internet]. 2011 29(1):24-26. [cited 2019 Feb 22]. Available from: http://www.nature.com/ articles/nbt.1754
53. Thorvaldsdottir H, Robinson JT, Mesirov JP. Integrative Genomics Viewer (IGV): high-performance genomics data visualization and exploration. Brief Bioinform [Internet]. 2013;14(2):178-192. [cited 2019 Feb 22]. Available from: https://academic.oup.com/bib/article-lookup/doi/10.1093/bib/bbs017

54. Anders S, Huber W. Differential expression analysis for sequence count data. Genome Biol [Internet]. 2010;11(10):R106. [cited 2019 Feb 22]. Available from: http://genomebiology.biomedcentral.com/articles/10.1186/gb-201 0-11-10-r106

55. Pfaffl MW. A new mathematical model for relative quantification in real-time RT-PCR. Nucleic Acids Res [Internet]. 2001;29(9):45e - 445. [cited 2014 Jul 24]. Available from: http://nar.oxfordjournals.org/content/29/9/e45.short

56. Ye K, Schulz MH, Long Q, Apweiler R, Ning Z. Pindel: a pattern growth approach to detect break points of large deletions and medium sized insertions from paired-end short reads. Bioinformatics [Internet]. 2009;25(21): 2865-2871. [cited 2019 Feb 22]. Available from: https://academic.oup.com/ bioinformatics/article-lookup/doi/10.1093/bioinformatics/btp394

\section{Publisher's Note}

Springer Nature remains neutral with regard to jurisdictional claims in published maps and institutional affiliations.
Ready to submit your research? Choose BMC and benefit from:

- fast, convenient online submission

- thorough peer review by experienced researchers in your field

- rapid publication on acceptance

- support for research data, including large and complex data types

- gold Open Access which fosters wider collaboration and increased citations

- maximum visibility for your research: over $100 \mathrm{M}$ website views per year

At $\mathrm{BMC}$, research is always in progress.

Learn more biomedcentral.com/submissions 